\title{
The Validity of Disease-Specific Quality of Life Attributions Among Adults with Multiple Chronic Conditions
}

\author{
John E. Ware Jr., ${ }^{1,2,}$, Barbara Gandek ${ }^{1,2}$ and Jeroan Allison ${ }^{1}$ \\ ${ }^{1}$ University of Massachusetts Medical School, Worcester, MA, USA \\ ${ }^{2}$ John Ware Research Group, Watertown, MA, USA
}

\begin{abstract}
Background: A crucial assumption underlying all disease-specific quality of life (QOL) measures, that patients can validly differentiate a specific disease in the presence of multiple chronic conditions, has not been tested using multiple methods. Our objective was to evaluate the convergent and discriminant validity of QOL attributions to specific diseases among adults with multiple chronic conditions (MCC).

Methods: Adults age 18 and older $(\mathrm{N}=4,480)$ sampled from eight pre-identified condition groups (asthma, COPD, angina/Ml with angina, congestive heart failure, diabetes, chronic kidney disease, osteoarthritis, rheumatoid arthritis) completed an Internet survey. Comorbid conditions were determined using a 35-condition checklist. Product-moment correlations were analyzed separately by pre-identified condition group using the multitrait-multimethod of construct validation, where traits were defined by 9-26 conditions and each condition was measured by two methods: disease severity rating and Disease-specific Quality of Life Impact Scale (QDIS) global rating. A third method (symptom or clinical marker) was available for the eight pre-identified conditions. Convergent validity was supported when correlations among different methods of measuring the same condition (trait) were substantial ( $r \geq 0.40)$. Discriminant validity was supported when correlations between the same and different methods of measuring different conditions were significantly lower than corresponding convergent correlations.

Results: In support of convergent validity, 22 of 24 convergent correlations were substantial $(r=0.38-0.84$, median=0.53). In support of discriminant validity, 833 of 924 tests $(90.2 \%)$ yielded significantly higher convergent than discriminant correlations across the eight pre-identified conditions. Exceptions to this pattern of results were most often observed for comorbid conditions within the same clinical area.

Conclusions: Collectively, convergent and discriminant test results support the construct validity of disease-specific QOL impact attributions across MCC within the eight pre-identified conditions. Noteworthy exceptions should be considered when interpreting some specific QOL impact attributions and warrant further study. Pursuit of a summary diseasespecific QOL impact score standardized across MCC is recommended.
\end{abstract}

Keywords: Patient-reported outcomes, Health-related quality of life, Disease-specific measures, Multiple chronic conditions, Validity, Multitrait-multimethod analysis.

\section{INTRODUCTION}

Multiple chronic conditions (MCC) have been defined as two or more concurrent chronic conditions that have an "adverse effect on health status, function, or quality of life" [1]. Presence of MCC is predictive of mortality, treatment outcomes, health care utilization and expenditures, disability, and quality of life (QOL) [2-4]. In addition to their use in prediction and case mix control in outcomes research, knowledge of MCC contributes to the understanding of patient complexity [5] and is a major consideration in establishing guidelines for quality of care [6]. Accordingly, estimates of MCC impact are an essential element in observational approaches to comparative effectiveness research [7] and a priority of information systems used in improving health care quality.

\footnotetext{
*Address correspondence to this author at the Department of Quantitative Health Sciences, University of Massachusetts Medical School, 368 Plantation Street, Worcester, MA 01605, USA; Tel: 508-856-8994;

E-mail: john.ware@umassmed.edu
}

For purposes of collective assessment, MCC have been simply counted $[8,9]$ or weighted according to a particular criterion, such as mortality [10] or health care utilization [11]. However, the increased emphasis on function and QOL portends a growing need for patientcentered measures of overall MCC burden [12]. For observational studies of QOL outcomes, it makes the most sense to adjust for MCC in terms of their patientreported impact on QOL, as opposed to simple counts or weights based on survival or cost.

QOL measures are conceptualized as generic, applying to all conditions and treatments, or diseasespecific, pertaining to a single disease or a disease cluster within a clinical area. What makes a measure disease-specific? A number of approaches have been employed with the goal of achieving disease-specific measures that are more clinically useful, actionable, and responsive in comparison with generic $\mathrm{QOL}$ measures. FDA guidelines for industry-sponsored clinical trials using patient-reported outcomes (PRO) [13] recommend assessment of symptoms that are specific, such as joint pain in arthritis [14] or dyspnea in 
respiratory disease [15]. Widely-accepted conceptual frameworks also require the representation of symptoms to achieve comprehensiveness in a PRO endpoint model [16]. However, symptoms may not be as specific as their inclusion in disease-specific measures implies; dyspnea measures for example are included in disease-specific measures for asthma [17], congestive heart failure [18] and kidney disease [19]. To the extent that symptoms are specific, they are useful in evaluating the convergent validity of diseasespecific QOL measures. Conceptually speaking, however, symptoms alone do not reflect QOL [20]. The content validity of disease-specific measures can be improved by better representing QOL outcomes known to be most affected by a disease; for example, physical functioning in osteoarthritis. Another measurement approach uses anatomic specificity, which may or may not achieve the desired disease specificity; for example, chest pain may be due to angina or due to chronic cough with COPD. Finally, simply asking patients to attribute the QOL impact of a specific disease is a patient-centered approach. In pursuit of this approach, content representation has been improved to the point that a primary difference between generic and disease-specific QOL measures is whether attributions are made to health in general or to a specific disease [21].

While generic QOL measures such as the EQ-5D [22], PROMIS [23], and the SF-36 Health Survey [24] allow illness burden and treatment effects to be compared across diseases, generic measures also have been characterized as being less responsive [25] and less useful in clinical research [16] than diseasespecific measures [13]. However, the lack of diseasespecific measures that are standardized across diseases has, up until now, precluded their use in meaningfully comparing disease-specific QOL impact or summarizing total MCC impact across diseases. There is a need for disease-specific QOL impact measures that fill the gap between symptom measures that conceptually are not QOL and generic QOL measures that are not disease-specific. One such effort, which had the goals of standardizing the content and scoring of measures of QOL impact attributed to specific conditions, was the Computerized Adaptive Assessment of Disease Impact (DICAT) project [26,27]. DICAT showed that disease-specific QOL measures could be constructed with standardized item content and scoring across diseases, thereby allowing diseasespecific QOL impact to be meaningfully compared across conditions. These disease-specific measures also had greater discriminant validity than generic $\mathrm{QOL}$ measures in distinguishing among severity levels, in studies of individual diseases [21]. Whether this approach works in the context of MCC is a question that is best addressed empirically and comprehensively.

In this paper, we use DICAT data to expand psychometric evaluations of disease-specific QOL measures beyond single-disease comparisons that ignore comorbidity. We use a multitrait(multi-disease)multimethod analytic approach to evaluate multiple methods of measurement for each disease across samples with multiple chronic conditions. This approach, which has advantages in testing construct validity as demonstrated in the fields of educational and psychological measurement [28], allows us to address a fundamental question underlying all uses of diseasespecific attributions in the measurement of QOL: Are disease-specific QOL attributions valid when multiple comorbid conditions are present? While the focus of this paper is on testing the convergent and discriminant validity of disease-specific QOL impact ratings, results may have implications for all efforts to aggregate disease-specific measures for purposes of patientcentered summary measurement of total MCC burden.

\section{METHODS}

\section{Sampling and Data Collection}

As described in detail elsewhere [21,29], data were collected from a probability-based sample aged 18 and older $(\mathrm{N}=5,418)$ recruited from the GfK (formerly Knowledge Networks (KN)) research panel of approximately 50,000 adults [30] during the DICAT project. Unlike convenience ("opt-in") panels, the KN panel is a probability-based sample, as recommended for Internet surveys [31]. It includes cell-phone only households, and panelists are provided with a computer and Internet connection if needed. Panelists had previously reported being diagnosed (Pre-ID) with any of nine conditions: respiratory disease (asthma, chronic obstructive pulmonary disease), cardiovascular disease (angina, myocardial infarction in past year (limited to those reporting comorbid angina in this analysis), congestive heart failure), diabetes, chronic kidney disease (CKD), and arthritis (osteoarthritis, rheumatoid arthritis). They were sampled to achieve at least 1,000 respondents within three (arthritis, diabetes and respiratory) groups in order to increase the number of sufficiently prevalent comorbid conditions, with smaller targets for less prevalent diagnoses 
(cardiovascular, CKD). Pre-ID conditions were confirmed at the start of the DICAT survey.

Panelists were recruited by $\mathrm{KN}$ via a routine invitation, which was followed by e-mail and IVR telephone reminders if necessary. Invitations were received by 9,160 pre-ID panelists, of whom 6,828 (74.5\%) opened an informed consent screen; 5,585 consented, and 5,418 (97\%) completed surveys. Survey protocols were designed to limit respondent burden (median $\leq 25$ minutes). For all protocols, modules were administered in the following order: generic QOL measures (not analyzed here), 35-item chronic condition checklist, global disease severity and QOL impact ratings for all conditions reported, and other previously validated (legacy) disease-specific measures. The chronic condition checklist and, therefore, estimates of comorbid conditions were limited to 35 conditions. Represented were all but two of the conditions (all but dementia and peripheral vascular disease) in the Charlson index [10], along with other conditions selected from large-scale health surveys such as the National Health Interview Survey (see Table 3 ). This analysis was limited to the 4,480 respondents who reported a pre-ID condition and completed the corresponding legacy measure used in convergent validation.

\section{Measures}

Development and standardization of QOL impact metrics across conditions required large pre-ID disease-specific item banks along with modules containing legacy measures specific to each pre-ID condition. Limits on respondent burden therefore precluded comprehensive disease-specific measurement for comorbid conditions on a par with that for pre-ID conditions. Each pre-identified condition was measured using three methods: (1) a previouslyvalidated symptom or clinical marker specific to each condition (see Table 1); (2) a standardized disease severity rating in response to "How would you rate the severity of your <condition> in the past 4 weeks?' with five response choices ranging from None to Very Severe; and (3) a standardized global rating of disease-specific QOL impact from the Disease-specific Quality of Life Impact Scale (QDIS) asking "In the past 4 weeks, how much did your <condition> limit your everyday activities or your quality of life?", with five response choices ranging from Not at all to Extremely $[21,29]$. Methods (2) and (3) were also measured for each comorbid condition reported. For comorbid obesity, a clinical marker was also measured (see
Table 1). In support of its reliability and validity, the global disease-specific QOL impact item has been shown to be very highly correlated $(r=0.96)$ with the total score from the full 49-item QDIS bank which measures 10 disease-specific QOL content areas, across the eight pre-ID groups [21]. Item-level missing data rates for the disease severity and disease-specific QOL impact ratings were low (median $=0.67 \%$, range 0.00-2.01\%). Test-retest (intraclass correlation coefficient, 5-14 days) reliability was satisfactory $\left(\operatorname{ICC}_{(3,1)}=0.74\right.$ for severity ratings, $\operatorname{ICC}_{(3,1)}=0.79$ for QDIS global impact ratings). For all methods reported here, higher scores indicate worse symptoms, severity or QOL impact, with the exception of eGFR, as noted in Table 1. Accordingly, all correlations were hypothesized to be positive, except those for eGFR.

\section{Analysis}

Data were analyzed separately for each pre-ID condition using the multitrait-multimethod (MTMM) approach to construct validation [32]. In contrast to common measurement evaluations based on a single method applied to a single trait (disease), the MTMM approach is ideal for studies of multiple comorbid conditions. Its strength is the production of a matrix of correlations among multiple traits, each measured by multiple methods sufficient to more rigorously evaluate construct validity. Traits were defined by chronic conditions and methods included up to three operational definitions (see above).

To evaluate convergent validity, a matrix of productmoment correlations among different methods of measuring the same condition (trait) was estimated for identical samples across three methods, within each pre-ID sample. These monotrait-heteromethod correlations are indicative of convergent validity when they are significantly different from zero and substantial in magnitude. Within each pre-ID condition, the stationarity of convergent correlations across comorbid pairs was evaluated to determine whether one convergent matrix could be used for all comparisons. For this decision, the matrix of convergent correlations based on all respondents for a pre-ID condition was compared with the same matrix of convergent correlation estimates for each smaller comorbid subsample. Because stationarity was confirmed collectively across pre-ID conditions (information available upon request), the convergent matrix for each full pre-ID sample is the basis for comparisons and the significance testing reported here. 


\section{Table 1: Variable Definitions}

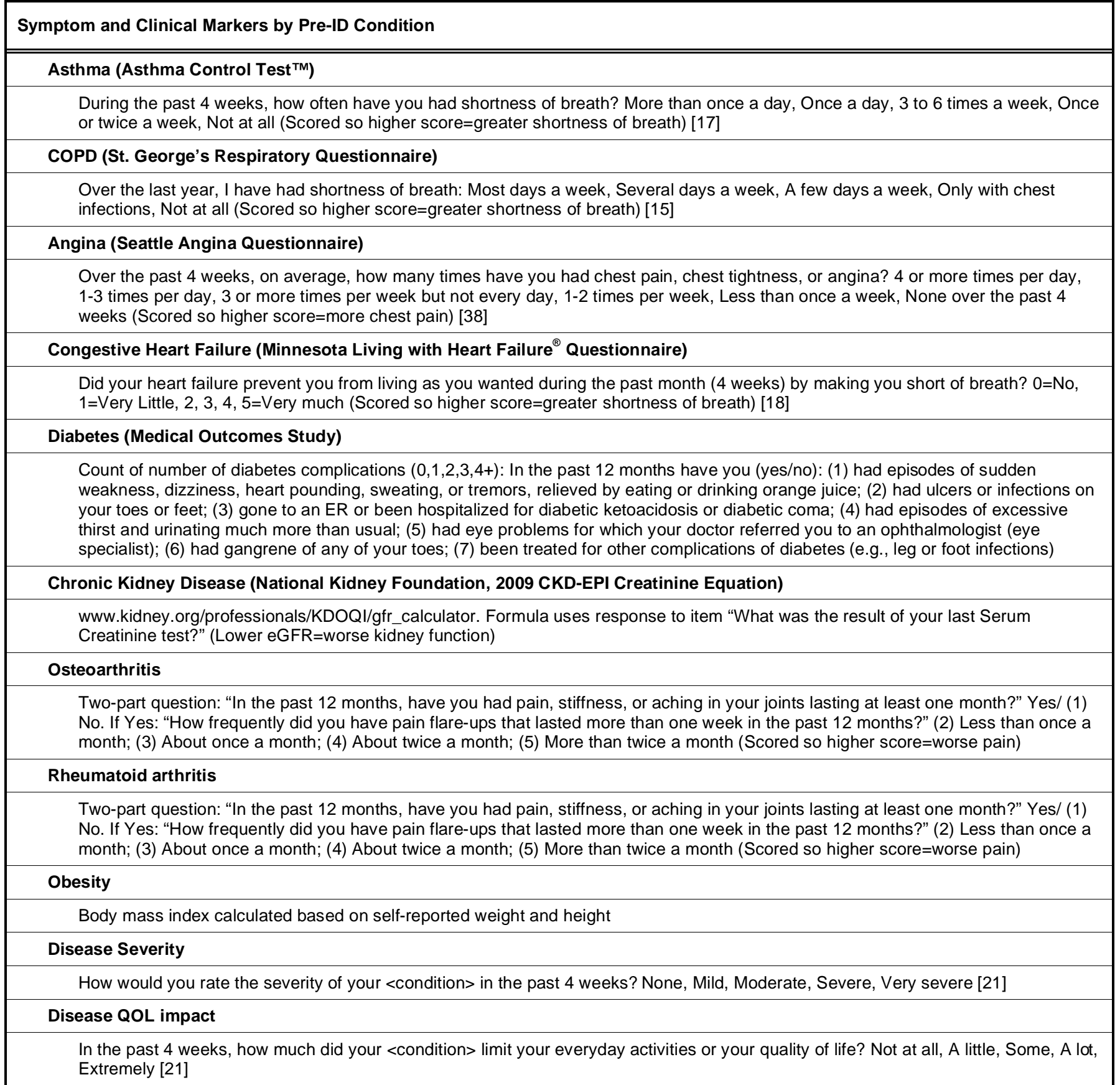

To evaluate discriminant validity across traits (conditions), matrices of product-moment correlations among the same (monomethod-heterotrait) and different (heteromethod-heterotrait) methods of measuring different conditions were estimated. Discriminant validity was supported to the extent that correlations between different conditions (heterotraits) were low in terms of absolute magnitude and significantly lower whether measured by the same or by different methods, in comparison with convergent correlations in the same matrix. In other words, a trait should correlate more highly with itself than with something else. Minimum sample sizes $(\mathrm{N} \geq 50)$ were established for all tests of convergent and discriminant validity.

Because 24 convergent correlations (3 for each condition) were compared with 924 discriminant correlations (51-153 across comorbid conditions), prespecified standards were applied to categorize results from convergent and discriminant tests. Convergent 
validity was supported by substantial $(r \geq 0.40)$ monotrait-heteromethod correlations. Discriminant validity evaluation was a 2-step process. First, discriminant validity was supported by low $(r \leq 0.30$, absolute magnitude) monomethod-heterotrait and heteromethod-heterotrait correlations. Second, discriminant validity was supported when discriminant (heterotrait) correlations were significantly lower $(p<0.05$, one-tailed test as documented in appended tables) in comparison with the corresponding convergent correlations. This second test was important because in most cases in which heterotrait correlations did not meet the $r \leq 0.30$ standard, they were still significantly lower than their corresponding convergent correlations, which is a pattern of results that supports construct validity.

Method effects, a possible contributor to discriminant failures, were examined by comparing correlations between two conditions measured by the same method (heterotrait-monomethod) relative to the same two conditions measured by two different methods (heterotrait-heteromethod). A method effect was indicated to the extent that heterotrait-

Table 2: Sample Characteristics

\begin{tabular}{|c|c|c|c|c|c|c|c|c|}
\hline & Asthma & COPD & Angina & CHF & Diabetes & CKD & OA & RA \\
\hline $\mathbf{N}$ & 742 & 274 & 221 & 271 & 1306 & 147 & 1026 & 493 \\
\hline Mean Age (SD) & $\begin{array}{c}48.3 \\
(16.3)\end{array}$ & $\begin{array}{c}63.9 \\
(10.6)\end{array}$ & $\begin{array}{c}64.9 \\
(10.3)\end{array}$ & $\begin{array}{c}66.9 \\
(10.7)\end{array}$ & $\begin{array}{c}60.2 \\
(11.9)\end{array}$ & $\begin{array}{c}64.7 \\
(12.5)\end{array}$ & $\begin{array}{c}62.7 \\
(10.6)\end{array}$ & $\begin{array}{c}60.3 \\
(12.2)\end{array}$ \\
\hline$\%$ Male & 34.0 & 43.8 & 58.8 & 53.1 & 51.8 & 53.1 & 35.9 & 35.1 \\
\hline \multicolumn{9}{|l|}{ Race/Ethnicity } \\
\hline Black non-Hispanic & 7.4 & 5.1 & 3.2 & 5.5 & 11.2 & 7.5 & 5.6 & 9.3 \\
\hline Hispanic & 11.7 & 3.3 & 2.3 & 2.6 & 6.2 & 3.4 & 4.6 & 6.9 \\
\hline Other non-Hispanic & 7.4 & 5.5 & 9.0 & 7.0 & 5.1 & 4.8 & 4.7 & 6.5 \\
\hline \multicolumn{9}{|l|}{ Education } \\
\hline College graduate & 42.1 & 24.1 & 38.0 & 34.7 & 38.6 & 39.4 & 47.1 & 33.1 \\
\hline \multicolumn{9}{|l|}{ Income } \\
\hline$<\$ 20,000$ & 12.4 & 23.7 & 12.2 & 15.1 & 10.7 & 9.5 & 9.6 & 16.6 \\
\hline$\$ 20,000-39,999$ & 17.5 & 26.3 & 28.0 & 25.8 & 21.8 & 26.5 & 20.1 & 25.2 \\
\hline$\$ 40,000-99,999$ & 48.3 & 40.2 & 48.0 & 48.0 & 52.2 & 50.4 & 48.7 & 43.8 \\
\hline$\$ 100,000_{+}$ & 21.8 & 9.8 & 11.8 & 11.1 & 15.3 & 13.6 & 21.6 & 14.4 \\
\hline \multicolumn{9}{|l|}{ Employment Status } \\
\hline Employed & 52.4 & 21.2 & 24.4 & 15.5 & 43.6 & 21.1 & 37.9 & 32.9 \\
\hline Mean PCS (SD) & $\begin{array}{l}47.5 \\
(9.9)\end{array}$ & $\begin{array}{c}39.6 \\
(11.4)\end{array}$ & $\begin{array}{c}40.1 \\
(11.0)\end{array}$ & $\begin{array}{c}39.2 \\
(10.0)\end{array}$ & $\begin{array}{l}47.0 \\
(9.5)\end{array}$ & $\begin{array}{c}40.8 \\
(10.8)\end{array}$ & $\begin{array}{l}43.5 \\
(9.8)\end{array}$ & $\begin{array}{c}41.7 \\
(10.4)\end{array}$ \\
\hline Mean MCS (SD) & $\begin{array}{c}48.1 \\
(10.2)\end{array}$ & $\begin{array}{c}46.7 \\
(11.5)\end{array}$ & $\begin{array}{c}48.1 \\
(10.5)\end{array}$ & $\begin{array}{l}49.5 \\
(9.6)\end{array}$ & $\begin{array}{l}50.6 \\
(9.0)\end{array}$ & $\begin{array}{l}49.4 \\
(9.8)\end{array}$ & $\begin{array}{l}49.9 \\
(9.7)\end{array}$ & $\begin{array}{l}48.7 \\
(9.8)\end{array}$ \\
\hline
\end{tabular}

Note: Angina is with or without myocardial infarction in past year. CKD is limited to Stages 3-5 using self-reported estimated glomerular filtration rate (eGFR).

PCS=SF-36 Physical Component Summary. MCS=SF-36 Mental Component Summary.

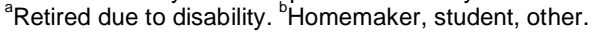


monomethod correlations were greater than heterotraitheteromethod correlations for the same two conditions.

\section{RESULTS}

\section{Sample Characteristics}

Characteristics of pre-identified disease groups are documented in Table 2. Overall, age ranged from 1893 (median $=61$ ), with $56.6 \%$ female and $80.1 \%$ nonHispanic white; $23.4 \%$ had an education level of high school graduate or less.

\section{Comorbid Conditions}

Table 3 summarizes the sample sizes for pairs of comorbid conditions for each pre-ID condition (columns) along with the frequency of each comorbid condition (rows); pairs with $\mathrm{N} \geq 50$ were included in the MTMM analyses. The number of comorbid conditions that could be tested varied according to the sample size for each pre-ID group $(\mathrm{N}=147-1,306)$ and group differences in comorbidity prevalence. Accordingly, the number of comorbidity tests within each pre-ID condition ranged from 14 to 25 , with the exception of CKD with only eight comorbid conditions. As documented in the right-most column of Table 3, five comorbidities were tested in every pre-ID group and 23 of the 35 were tested at least four times. Only six could not be tested.

\section{Construct Validity}

To illustrate how analyses were performed and results were interpreted, Table 4 presents results for the pre-ID asthma group and the first two comorbid conditions (obesity and diabetes). This table includes sample sizes for asthma and for subsamples with asthma and comorbid obesity or diabetes (CC). The rows present results for the three different methods of measuring asthma (shortness of breath (As1), severity (As2) and QOL impact (As3)) along with three methods for comorbid obesity and two methods for comorbid diabetes, as documented (see Methods, Table 1 and Appendix Table A1). The first three columns present results for the three methods of measuring asthma (As1, As2, As3). Entries for the rightmost two columns vary by comorbid condition; for example, for the obesity rows, $\mathrm{CC} 1$ is Ob1 (Body mass index) and CC2 is Ob2 (Obesity severity). For the diabetes rows, CC2 is Di2 (Diabetes severity); no symptom measure or clinical marker (CC1) was available for comorbid diabetes when the pre-ID condition was asthma. No CC1 correlations are presented for all comorbid conditions other than obesity, by design.
Monotrait-heteromethod correlations among the three asthma measurement methods, which are contained in the triangle, support the convergent validity of asthma-specific attributions because all convergent correlations for asthma in the triangle were: (a) statistically significant (bolded) and (b) substantial in magnitude $(r=0.52-0.70$, median $=0.53)$. In every matrix, the median convergent correlation serves as the referent for purposes of significance testing. Further, in support of discriminant validity: (c) heterotrait correlations that should be low within the box were low for 14 of 15 estimates (ranging from 0.04-0.34, median=0.13); the one exception is underlined; and (d) all boxed estimates are significantly $(p<0.05)$ lower than the referent (median) convergent correlation in the triangle. If any of the latter had failed this second test, they would have been starred ( $\left.{ }^{*}\right)$. Taken together, these results support the construct validity of these disease-specific attributions. Convergent correlations for comorbid conditions are presented in the right-most two columns, including three for obesity (the only comorbid condition measured by three methods) and one for diabetes (the correlation between its two methods). Complete results from convergent and discriminant tests for asthma, which are consistent with results in this example, are documented in Appendix Table A1. Complete results for the other seven pre-ID conditions are documented in Appendix Tables A2 to A8.

Applying MTMM logic and specific standards illustrated above, Table $\mathbf{5}$ summarizes appended results across all eight pre-ID conditions. Collectively, results support the construct validity of conditionspecific QOL impact attributions, although there were noteworthy exceptions. First, with respect to convergent validity: (a) the eight sets of three monotrait-heteromethod correlations for pre-ID groups were all statistically significant; and (b) 22 of 24 estimates were substantial in magnitude $(r=0.38-0.84$, median=0.53). The two exceptions were observed for diabetes and CKD. In support of discriminant validity: (a) across 34-102 heterotrait-heteromethod tests per group, most were below the standard required for discriminant validity $(r \leq 0.30)$ with medians of $0.18-0.29$; and (b) across 17-51 heterotrait-monomethod tests per group, most correlations were below the standard of $r \leq 0.30$, with medians ranging $0.17-0.41$, as hypothesized. Finally, in support of convergentdiscriminant validity, heterotrait (heteromethod and monomethod) correlations were significantly lower than referent convergent correlations in $71-100 \%$ 
Table 3: Frequency of Pairs of Comorbid Chronic Conditions

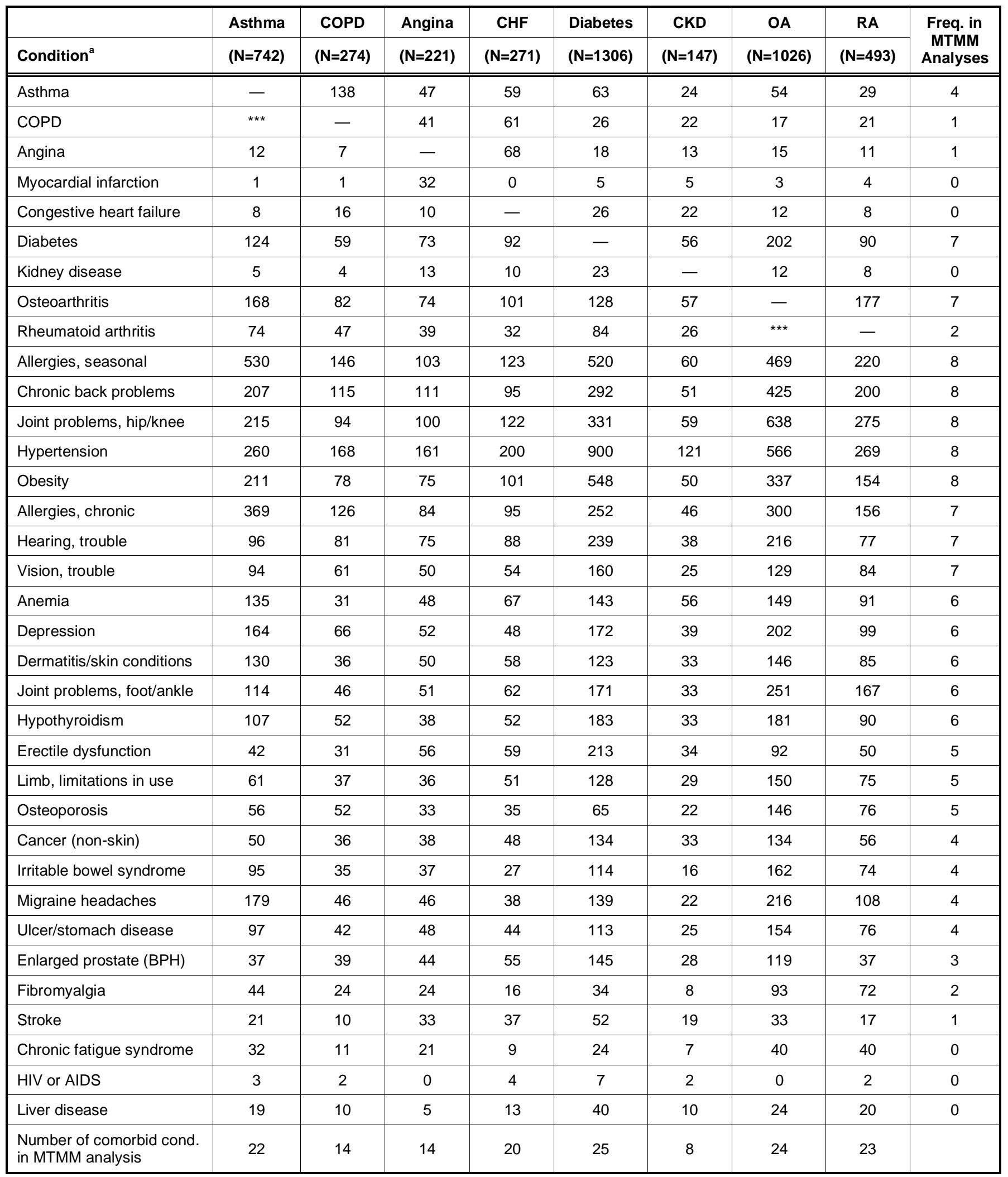

Note: Angina is with or without myocardial infarction in past year. CKD is limited to Stages 3-5 using self-reported eGFR.

${ }_{* * *}$ Comorbid condition not included for this pre-ID group.

${ }^{a}$ For most conditions, the survey item included words in addition to the column labels; full item content available upon request. 
Table 4: Sample of Results for Methods of Measuring Asthma and Prevalent Comorbid Conditions

\begin{tabular}{|c|c|c|c|c|c|}
\hline & \multicolumn{3}{|c|}{ Asthma } & \multicolumn{2}{|c|}{ Comorbid Condition } \\
\hline \multicolumn{6}{|l|}{ Asthma ( $\mathrm{N}=742)$} \\
\hline \multicolumn{6}{|l|}{ As1 Shortness of breath ${ }^{a}$} \\
\hline As2 Asthma severity & 0.52 & & & & \\
\hline Ob1 Body mass index & 0.17 & 0.04 & 0.03 & & \\
\hline Ob2 Obesity severity & 0.22 & 0.11 & 0.16 & 0.46 & \\
\hline Ob3 Obesity QOL impact & $\underline{0.34}$ & 0.13 & 0.20 & 0.37 & 0.66 \\
\hline \multicolumn{6}{|l|}{ Diabetes $(\mathrm{N}=124)$} \\
\hline
\end{tabular}

CC1 = Symptom measure for comorbid condition; CC2 = Severity measure for comorbid condition.

Higher scores on all measures indicate greater disease severity or impact.

a Shortness of breath defined in Table 1. Scored so higher score=greater shortness of breath.

All correlations used to test convergent validity are bolded. Correlations within the triangle are for the pre-ID condition.

Heterotrait correlations greater than 0.30 in boxed discriminant tests are underlined.

Heterotrait correlations not significantly $(p<0.05)$ lower than their referent convergent correlation are starred $\left(^{*}\right)$. Heterotrait correlations $r>0.46$ failed convergentdiscriminant 1-tailed test $(p<0.05)$. Median $(r=0.53)$ correlation from convergent triangle selected for convergent-discriminant comparisons.

Table 5: Summary Results and Success Rates for Multitrait-Multimethod Correlational Tests of Convergent and Discriminant Validity, Eight Pre-Identified Disease Groups

\begin{tabular}{|c|c|c|c|c|c|c|c|c|c|c|c|c|c|}
\hline \multirow[b]{3}{*}{ Disease } & \multirow[b]{3}{*}{$\mathbf{N}$} & \multirow[b]{3}{*}{$\mathrm{CC}$} & \multirow{2}{*}{\multicolumn{3}{|c|}{ Convergent validity $^{a}$}} & \multicolumn{8}{|c|}{ Discriminant validity (Heterotrait) } \\
\hline & & & & & & \multicolumn{3}{|c|}{ Heteromethod $^{\mathrm{b}}$} & \multicolumn{3}{|c|}{ Monomethod $^{c}$} & \multicolumn{2}{|c|}{ Success $^{d}$} \\
\hline & & & $\#$ & $\operatorname{Med}^{\mathrm{e}}$ & Range $^{e}$ & $\#$ & Med & Range & $\#$ & Med & Range & Ratio & $\%$ \\
\hline COPD & 274 & 14 & 3 & 0.62 & $.60-.84$ & 58 & 0.26 & $.02-.72$ & 29 & 0.41 & $.12-.79$ & $77 / 87$ & 89 \\
\hline Angina & 221 & 14 & 3 & 0.60 & $.56-.77$ & 58 & 0.25 & $.00-.49$ & 29 & 0.29 & $.05-.65$ & $83 / 87$ & 95 \\
\hline Diabetes & 1306 & 25 & 3 & 0.42 & $.38-.52$ & 102 & 0.18 & $.01-.37$ & 51 & 0.25 & $.02-.51$ & $144 / 153$ & 94 \\
\hline CKD & 147 & 8 & 3 & 0.45 & $.39-.72$ & 34 & 0.20 & $.02-.48$ & 17 & 0.26 & $.00-.49$ & $36 / 51$ & 71 \\
\hline OA & 1026 & 24 & 3 & 0.51 & $.49-.75$ & 98 & 0.21 & $.04-.60$ & 49 & 0.26 & $.05-.71$ & $126 / 147$ & 86 \\
\hline $\mathrm{RA}$ & 493 & 23 & 3 & 0.53 & $.49-.78$ & 94 & 0.29 & $.00-.54$ & 47 & 0.33 & $.03-.55$ & $120 / 141$ & 85 \\
\hline
\end{tabular}

Note: $\mathrm{CC}=$ Number of comorbid conditions with $\mathrm{N} \geq 50$; \#=Number of tests of each type; $\mathrm{COPD}=$ chronic obstructive pulmonary disease; $\mathrm{CHF}=$ congestive heart failure; $\mathrm{CKD}=$ chronic kidney disease; $\mathrm{OA}=$ osteoarthritis; $\mathrm{RA}=$ rheumatoid arthritis.

${ }^{a} \mathrm{MTHM}=$ Monotrait-heteromethod, same disease-different methods (convergent validity)

${ }^{\mathrm{b}} \mathrm{HTHM}=$ Heterotrait-heteromethod, different diseases-different methods (discriminant validity)

'HTMM=Heterotrait-monomethod, different diseases-same method (method effect)

${ }^{d}$ Convergent/discriminant success ratio is the number of heterotrait correlations that were significantly lower than the referent (median) convergent correlation divided by the total number of discriminant tests in each disease group. The overall success ratio was $833 / 924=90.2 \%$.

Median and range (lowest to highest) correlations, absolute value.

(median=90\%) of tests across the eight groups (see appended tables for detailed results summarized in Table 5). In other words, in 9 out of 10 cases in which correlations between different conditions (heterotraits) were hypothesized to be low, they were significantly lower than their corresponding convergent correlations. This pattern of results supports construct (convergentdiscriminant) validity.
As summarized in the rightmost column of Table 5, the lowest convergent-discriminant success rates were observed for COPD (89\%), CKD (71\%), OA (86\%), and RA (85\%). Other clues apparent for COPD include one of the only two median heterotrait-monomethod correlations that was substantial in magnitude (see third set of columns) and also the very high correlations at the top of the ranges $(r=0.72$ and 0.79$)$ for 
heterotrait-heteromethod and heterotrait-monomethod correlations, all of which should be low for discriminating measures. Inspection of appended Table A2 reveals that two comorbid conditions (asthma and depression) accounted for most significant failures to discriminate observed for severity and QOL impact rating methods of measuring COPD. The shortness of breath method produced mixed results with the two asthma ratings. For osteoarthritis (OA), appended Table A7 reveals that comorbid back problems, fibromyalgia, joint problems (foot/ankle, hip/knee), limitations in limb usage and osteoporosis accounted for all exceptions for OA severity and QOL impact rating methods. A cross-tabulation (not reported) of self-reports of $O A$ versus hip/knee joint problems and limb limitations suggested that the latter two conditions were perceived as subsets of OA. The same pattern of results within the RA group was observed for comorbid back problems, fibromyalgia, joint problems (foot/ankle, hip/knee) and osteoporosis along with other comorbid conditions (see appended Table A8).

Convergent correlations for the three methods of measuring CKD were among the lowest observed and this group had the smallest sample. Although the convergent correlations for eGFR were substantial in magnitude, they were not significantly larger than eGFR correlations with ratings of back problems, and CKD severity and QOL impact ratings failed discriminant tests in relation to ratings of comorbid anemia, back problems, and other conditions (see appended Table A6).

The third set of comparisons in Table 5 (heterotraitmonomethod) distinguishes 17-51 correlations per disease from corresponding heterotrait-heteromethod correlations (second set of comparisons) for purposes of testing for any method effects. To the extent that the third set was larger than the second set, methods effects are supported. The most noteworthy method effect, observed for COPD, is documented above.

\section{DISCUSSION AND CONCLUSIONS}

Results from 22 of 24 convergent (multiple methods for same condition) tests supported the construct validity of disease-specific QOL impact attributions across eight disease groups, for which three-fourths reported three or more MCC. Further, across more than 900 discriminant tests, 9 out of 10 results supported construct validity. With some exceptions, these results support the validity of a global diseasespecific QOL impact score based on the attribution to each condition for purposes of monitoring QOL outcomes, as well as the aggregation of impact ratings to estimate total MCC burden in QOL terms. We discuss these issues along with limitations of the study and summarize our conclusions below.

\section{Lessons from Noteworthy Exceptions}

Variability and exceptions in patterns of discriminant validity findings provide clues for further studies of the validity of QOL impact attributions. Among the conditions with the lowest convergent-discriminant success rates - CKD (71\%), RA (85\%), OA (86\%) and COPD $(89 \%)$ - several patterns stand out as reasons for caution in interpretations and potentially fruitful targets of additional research. For example, among the weakest evidence of discriminant validity were correlations between multiple methods studied among patients with both COPD and asthma. One clue warranting more in-depth analysis is that COPD and asthma have a specific symptom in common shortness of breath - that correlated substantially with measures of the quality of life impact attributed to both conditions. The practical implication is very high correlations ( $r=0.67-0.79)$ between ratings of different conditions that should be low $(r \leq 0.30)$ according to the discriminant validity standard. Distinctions between these conditions have been debated, which suggests that there may be clinical explanations for any lack of distinction; regardless, results reported here suggest that patient ratings of severity and QOL impact should be interpreted with caution when both of these specific conditions are present, which was a common occurrence in the current study.

Another example is congestive heart failure and comorbid angina. Although convergent correlations for $\mathrm{CHF}$ were more than substantial $(\mathrm{r}=0.50-0.77)$ and the overall success rate for CHF was high (112/123 tests, $91 \%$ ), all six of the heterotrait estimates for comorbid angina that should be low $(r \leq 0.30)$ according to the discriminant validity standard were substantial $(r=0.47$ 0.55 ) and none were significantly lower than the corresponding convergent correlations. Analogous to the COPD-asthma example above, $\mathrm{CHF}$ and angina ratings consistently failed in discriminant tests of validity and should be interpreted with caution when both conditions are present. These patterns of results underscore the importance of comprehensive multitraitmultimethod validations of tools used in studies of MCC and also call into question how specific some widelyused disease-specific measures actually are. The addition of correlation estimates using more objective 
clinical measures for comorbid conditions in future studies would make it possible to better interpret results and evaluate alternate explanations.

Another pattern of exceptions may be the result of asking patients to evaluate conditions that are a subset of another, for example, joint problems (hip/knee) and limitations in limb usage as conditions within osteoarthritis (OA). However, this does not explain high correlations observed between QOL impact for OA and other conditions such as fibromyalgia. A similar pattern of results was observed within the RA group for comorbid back problems, fibromyalgia, joint problems (foot/ankle and hip/knee) and osteoporosis, among others. These exceptions also suggest the need for caution in interpreting patient attributions of the QOL impact of each condition in the presence of these specific MCC.

Convergent correlations for the three methods of measuring CKD were among the lowest observed. To the extent that convergence is weak, success in tests of discriminant validity is less likely. Although the convergent correlations for eGFR were substantial in magnitude, they were not significantly larger than the discriminant correlations for ratings of back problems; also, both CKD severity and QOL impact ratings failed discriminant tests in relations to ratings of comorbid anemia and back problems. Are fatigue or joint pain underlying problems common to CKD and these comorbid conditions? Suggesting that CKD-specific attributions are CKD-specific, a study comparing them with generic measures across clinically-determined eGFR groups found that the CKD QDIS measures were the most valid of those studied [33]. There also is strong evidence that CKD-specific QOL ratings are more valid in discriminating across severity levels, in comparison with generic physical and mental measures with attributions to health in general [21,34].

The value of replications across multiple conditions and multiple methods in interpreting results is also illustrated in the appended tables. For example, the failure of ratings attributed to comorbid depression in three of six discriminant tests within the COPD group might have been interpreted as evidence that depressed patients make less valid attributions. However, among the five other pre-ID groups (angina, asthma, diabetes, $O A$ and RA) with samples sufficient to analyze comorbid depression, 28 of $30(93.3 \%)$ tests met the criteria (corresponding convergent significantly higher than discriminant (heterotrait) correlation). An alternative explanation for the COPD findings, consistent with some prior research [35], is a substantial association between traits (i.e., COPD and depression) as experienced by patients.

\section{Methodological Issues}

Multiple standards of convergent-discriminant validity were applied because of the complexity of evaluating construct validity. In a correlated world, valid methods of measuring each of two different traits (i.e., pairs of chronic conditions) should be correlated to the extent that the traits are correlated. If so, the first standard requiring low $(r \leq 0.30)$ correlations between discriminating measures of different traits will not be met. For this reason, the second standard is based on formal tests of whether corresponding convergent correlations across different methods of measuring the same condition are significantly higher than those for comorbid conditions. For example, within the asthma group, although many of the discriminant (heterotrait) correlations with comorbid conditions exceeded the $r \leq 0.30$ standard, tests of the second standard revealed that $100 \%$ were significantly lower than the corresponding convergent correlation.

The MTMM approach applied here is in contrast to typical validation paradigms that yield construct evidence of validity in the form of correlations between different methods in single-disease studies and or that link different conditions to a generic measure. The most common approaches have been single-disease comparisons of groups differing in severity within that disease, without regard to the presence or influence of MCC. Better ways to test measurement specificity (discriminant validity) are to compare convergent and discriminant tests, or to compare disease-specific and generic measures in relation to a specific criterion. Otherwise, results say little or nothing about specificity of measurement or discriminant validity. Despite their advantages, validations of disease-specific PRO measures employing multiple methods across samples with multiple chronic conditions are rare. To the best of our knowledge, this is the first attempt at replicating multiple methods within each disease across multiple chronic conditions.

\section{LIMITATIONS}

A limitation of this study is reliance entirely on selfreport for disease severity and impact as well as legacy disease-specific measures. Although self-report methods have been useful in validation, results may have been different if "criteria" had been based on 
independent clinical judgement. However, it is reasonable to expect that mere response bias would not account for the superior discriminant validity of a self-report for one disease in comparison with the same report for another comorbid condition, and the data consistently support this expectation. Examples of method tests that were more distinct than the two rating methods were the body mass index method for obesity and eGFR for CKD. Results for obesity were strong in discriminating across all pre-identified conditions studied. Regardless, future validity tests would be strengthened by using clinician-reported methods and other more independent and objective methods, which are also likely to make study findings more useful in establishing interpretation guidelines. An example is a recent study of the validity of $\mathrm{QOL}$ attributions to smoking that used biomarkers of smoking exposure as a method of construct validation [36].

Another limitation is the lack of specific symptoms and more objective markers as methods of measuring comorbid conditions. Because of constraints on respondent burden during the DICAT study, which required large disease-specific $\mathrm{QOL}$ impact item banks and other disease-specific surveys, only two ratings (severity, QOL impact) were possible for almost all comorbid conditions. High priority should be placed on achieving at least three methods for each chronic condition and on making those methods as distinctly different as possible, including clinical metrics of interest to clinical researchers and stronger convergent tests. Another advantage of three or more methods per trait (condition) is the identification of confirmatory multitrait-multimethod models that enable formal tests of model fit indicative of convergent and discriminant validity [28].

\section{SUGGESTIONS FOR FUTURE RESEARCH}

Regardless of whether specificity is only moderate, in the aggregate a summary MCC QOL impact estimate including moderately discriminating measures may still provide a very useful QOL-based comorbidity index for use in health outcomes research. Its advantages include a QOL metric that is standardized (across diseases) and calibrated in terms of QOL impact, as opposed to a mortality weight such as that used in the Charlson index. The standardized global QOL impact measures analyzed here may also enable a pathway to more directly comparable disease-specific QOL impact measures that are practical enough to enable an individualized summary measure of QOL impact across multiple comorbid conditions. However, this advance presumes that disease-specific attributions are valid in the presence of multiple comorbid conditions. They appear to be sufficiently so to warrant further research addressing the issues discussed above as well as addressing different aggregation approaches and we recommend such further investigation.

Screening to meet sample quotas sufficient to analyze more permutations of MCC beyond the samples of pairs of conditions that were possible within the DICAT database should be a priority for future research. For example, no tests could be performed for six comorbid conditions (see Table 3). Further, 3disease models were beyond the scope of the current paper, although three-fourths of the pre-ID sample reported three or more conditions. Inspection of sample sizes for the most prevalent MCC combinations indicated that many are large enough for 3-disease MTMM correlation matrices by adding a third condition to a pre-ID condition/comorbid pair reported here. Exploring these MCC triads would be very useful in planning future studies using the MTMM approach.

Some of the advantages of standardization of content and scoring of MCC using QOL-based weights [37] have been realized using generic QOL measures, because the generic physical component of QOL is related to counts of conditions and conditions weighted for QOL impact. The theoretical advantage of diseasespecific QOL weighting is that the estimates are more specific to each index condition and, therefore, more attributable and actionable in relation to that specific condition. Carrying this logic another step forward, advantages of individualized over population weights for each MCC may be a substantial further gain in precision. The rating methods evaluated here make individualized MCC QOL impact estimates practical and the overall pattern of results suggests they may have sufficient construct validity.

\section{CONCLUSIONS}

Although there are noteworthy exceptions, collective results reported here indicate very high rates of success in convergent and divergent tests, in support of the construct validity of disease-specific QOL impact attributions across multiple chronic conditions. Hence, a global QOL impact measure that uses diseasespecific attribution is a valid addition to the toolkit for monitoring patient-reported outcomes for each of the conditions studied here. Further, results support aggregating disease-specific QOL impact ratings 
across conditions to estimate total MCC burden in QOL terms. For the pairs of MCC yielding noteworthy exceptions, the interpretation of some specific QOL impact attributions should be pursued with caution and those exceptions should be the focus of further studies using the multitrait-multimethod approach, strengthened with the inclusion of clinical markers and other objective methods to supplement the QOL ratings studied here. With respect to the overall objective of this study, we conclude that the collective pattern of results supports the validity of disease-specific quality of life attributions sufficiently to warrant their use among adults with multiple chronic conditions.

\section{ACKNOWLEDGEMENTS}

Preparation of this paper was supported by AHRQ grant R21-HS023117 (J Ware, PI) and by John Ware Research Group (JWRG) from its own research funds. QDIS development and evaluation also were supported by a National Institute on Aging SBIR grant (R44-
AG025589, J Ware, PI). The authors acknowledge the research support of Nina Deng EdD and Rick Guyer $\mathrm{PhD}$, the technological management of Josh Ryan, and the support of GfK, USA (formerly Knowledge Networks) in managing the complicated DICAT study design and data collection process. EQ-5D'M is a trademark of the EuroQol Research Foundation. PROMIS $^{\circledR}$ is a registered trademark of the U.S. Department of Health and Human Services. QDIS ${ }^{\circledR}$ is a registered trademark of JWRG. SF- $366^{\circledR}$ is a registered trademark of the Medical Outcomes Trust. All other trademarks are the property of their respective owners.

\section{CONFLICT OF INTEREST}

Dr. Ware is Chief Science Officer and shareholder of the John Ware Research Group (JWRG), which has been funded by NIH SBIR grants and unrestricted industry grants. Dr. Gandek is an employee and shareholder of JWRG.

\section{APPENDIX}

Table A1: Asthma: Correlations with Prevalent Comorbid Conditions

\begin{tabular}{|c|c|c|c|c|c|}
\hline & \multicolumn{3}{|c|}{ Asthma } & \multicolumn{2}{|c|}{ Comorbid Condition } \\
\hline & As1 & As2 & As3 & CC1 & CC2 \\
\hline \multicolumn{6}{|l|}{ Asthma $(\mathrm{N}=742)$} \\
\hline \multicolumn{6}{|l|}{ As1 Shortness of breath ${ }^{a}$} \\
\hline As2 Asthma severity & 0.52 & & & & \\
\hline As3 Asthma QOL impact & 0.53 & 0.70 & & & \\
\hline \multicolumn{6}{|l|}{ Obesity $(\mathrm{N}=211)$} \\
\hline Ob1 Body mass index & 0.17 & 0.04 & 0.03 & & \\
\hline Ob2 Obesity severity & 0.22 & 0.11 & 0.16 & 0.46 & \\
\hline Ob3 Obesity QOL impact & 0.34 & 0.13 & 0.20 & 0.37 & 0.66 \\
\hline \multicolumn{6}{|l|}{ Diabetes $(\mathrm{N}=124)$} \\
\hline Di2 Diabetes severity & 0.05 & 0.07 & 0.10 & --- & \\
\hline Di3 Diabetes QOL impact & 0.21 & 0.09 & 0.13 & --- & 0.52 \\
\hline \multicolumn{6}{|l|}{ Osteoarthritis $(\mathrm{N}=168)$} \\
\hline OA2 OA severity & 0.24 & 0.23 & 0.22 & --- & \\
\hline OA3 OA QOL impact & 0.31 & 0.25 & 0.30 & --- & 0.73 \\
\hline \multicolumn{6}{|l|}{ Rheumatoid arthritis $(\mathrm{N}=74)$} \\
\hline RA2 RA severity & 0.41 & 0.42 & 0.38 & --- & \\
\hline RA3 RA QOL impact & 0.37 & 0.39 & 0.38 & --- & 0.84 \\
\hline \multicolumn{6}{|l|}{ Allergies-chronic (N=369) } \\
\hline Allc2 Allergy-chronic severity & 0.34 & 0.32 & 0.35 & --- & \\
\hline Allc3 Allergy-chronic QOL impact & 0.32 & 0.32 & 0.43 & --- & 0.73 \\
\hline \multicolumn{6}{|l|}{ Allergies-seasonal $(\mathrm{N}=530)$} \\
\hline Alls2 Allergy-seasonal severity & 0.26 & 0.27 & 0.32 & --- & \\
\hline Alls3 Allergy-seasonal QOL impact & 0.28 & 0.27 & 0.36 & --- & 0.76 \\
\hline \multicolumn{6}{|l|}{ Anemia $(\mathrm{N}=135)$} \\
\hline An2 Anemia severity & 0.07 & 0.12 & 0.20 & --- & \\
\hline An3 Anemia QOL impact & 0.14 & 0.24 & 0.31 & --- & 0.65 \\
\hline
\end{tabular}


(Table A1). Continued.

\begin{tabular}{|c|c|c|c|c|c|}
\hline & \multicolumn{3}{|c|}{ Asthma } & \multicolumn{2}{|c|}{ Comorbid Condition } \\
\hline \multicolumn{6}{|l|}{ Cancer, non-skin $(\mathrm{N}=50)$} \\
\hline Ca3 Cancer QOL impact & 0.00 & 0.13 & 0.21 & --- & 0.67 \\
\hline \multicolumn{6}{|l|}{ Chronic back problems (N=207) } \\
\hline \multicolumn{6}{|l|}{ Depression $(\mathrm{N}=164)$} \\
\hline De2 Depression severity & 0.26 & 0.12 & 0.20 & -- & \\
\hline De3 Depression QOL impact & 0.23 & 0.10 & 0.16 & --- & 0.87 \\
\hline \multicolumn{6}{|l|}{ Dermatitis/skin conditions $(\mathrm{N}=130)$} \\
\hline He3 Hearing QOL impact & 0.16 & 0.14 & 0.21 & --- & 0.61 \\
\hline \multicolumn{6}{|l|}{ Hypertension $(\mathrm{N}=260)$} \\
\hline Hy2 Hypertension severity & 0.27 & 0.38 & 0.40 & --- & \\
\hline Hy3 Hypertension QOL impact & 0.29 & 0.34 & 0.41 & -- & 0.55 \\
\hline \multicolumn{6}{|l|}{ Hypothyroidism (N=107) } \\
\hline Th2 Hypothyroidism severity & 0.16 & 0.17 & 0.13 & -- & \\
\hline Th3 Hypothyroidism QOL impact & 0.25 & 0.23 & 0.23 & -- & 0.67 \\
\hline \multicolumn{6}{|l|}{ Irritable bowel syndrome $(\mathrm{N}=95)$} \\
\hline Ib2 IBS severity & 0.21 & 0.32 & 0.16 & --- & \\
\hline Hk3 Hip/knee QOL impact & 0.24 & 0.19 & 0.18 & --- & 0.81 \\
\hline \multicolumn{6}{|l|}{ Limb, limitations in use $(\mathrm{N}=61)$} \\
\hline Lm2 Limb severity & 0.22 & 0.21 & 0.07 & --- & \\
\hline Lm3 Limb QOL impact & 0.21 & 0.30 & 0.15 & --- & 0.88 \\
\hline \multicolumn{6}{|l|}{ Migraine headaches $(\mathrm{N}=179)$} \\
\hline Mi2 Migraine severity & 0.21 & 0.19 & 0.20 & --- & \\
\hline Mi3 Migraine QOL impact & 0.26 & 0.27 & 0.29 & --- & 0.90 \\
\hline \multicolumn{6}{|l|}{ Osteoporosis (N=56) } \\
\hline Os2 Osteoporosis severity & 0.18 & 0.24 & 0.17 & --- & \\
\hline Os3 Osteoporosis QOL impact & 0.04 & 0.28 & 0.17 & --- & 0.67 \\
\hline \multicolumn{6}{|l|}{ Ulcer/stomach disease $(\mathrm{N}=97)$} \\
\hline UI2 Ulcer/stomach severity & 0.26 & 0.24 & 0.11 & --- & \\
\hline UI3 Ulcer/stomach QOL impact & 0.29 & 0.26 & 0.15 & --- & 0.76 \\
\hline \multicolumn{6}{|l|}{ Vision, trouble $(\mathrm{N}=94)$} \\
\hline Vi2 Vision severity & 0.16 & 0.19 & 0.09 & --- & \\
\hline Vi3 Vision QOL impact & 0.28 & 0.31 & 0.25 & --- & 0.60 \\
\hline
\end{tabular}

$\mathrm{CC} 1$ = Symptom measure for comorbid condition; CC2 = Severity measure for comorbid condition.

Higher scores on severity and impact items indicate greater disease severity or greater disease impact.

${ }^{a}$ Shortness of breath defined in Table 1. Higher scores indicate greater shortness of breath.

*Heterotrait correlations $r>0.46$ (absolute value) failed convergent-discriminant 1-tailed test. Median ( $r=0.53$ ) correlation from convergent triangle selected for convergent-discriminant comparisons. 
Table A2: COPD: Correlations with Prevalent Comorbid Conditions

\begin{tabular}{|c|c|c|c|c|c|}
\hline & \multicolumn{3}{|c|}{ COPD } & \multicolumn{2}{|c|}{ Comorbid Condition } \\
\hline & Co1 & Co2 & Co3 & CC1 & CC2 \\
\hline \multicolumn{6}{|l|}{ COPD (N=274) } \\
\hline \multicolumn{6}{|l|}{ Co1 Shortness of breath ${ }^{a}$} \\
\hline Co2 COPD severity & 0.60 & & & & \\
\hline Co3 COPD QOL impact & 0.62 & 0.84 & & & \\
\hline \multicolumn{6}{|l|}{ Obesity (N=78) } \\
\hline Ob1 Body mass index & 0.12 & 0.10 & 0.15 & & \\
\hline Ob2 Obesity severity & 0.13 & 0.31 & 0.32 & 0.67 & \\
\hline Ob3 Obesity QOL impact & 0.25 & 0.38 & 0.45 & 0.68 & 0.82 \\
\hline \multicolumn{6}{|l|}{ Asthma $(\mathrm{N}=138)$} \\
\hline As2 Asthma severity & 0.44 & $0.67^{*}$ & $0.67^{\star}$ & --- & \\
\hline As3 Asthma QOL impact & $0.52^{*}$ & $0.72^{*}$ & $0.79^{*}$ & --- & 0.86 \\
\hline \multicolumn{6}{|l|}{ Diabetes $(N=59)$} \\
\hline Di2 Diabetes severity & 0.08 & 0.32 & 0.31 & --- & \\
\hline Di3 Diabetes QOL impact & 0.25 & 0.45 & 0.50 & --- & 0.76 \\
\hline \multicolumn{6}{|l|}{ Osteoarthritis $(\mathrm{N}=82)$} \\
\hline OA2 OA severity & 0.08 & 0.21 & 0.27 & --- & \\
\hline OA3 OA QOL impact & 0.19 & 0.24 & 0.36 & --- & 0.80 \\
\hline \multicolumn{6}{|l|}{ Allergies-chronic $(\mathrm{N}=126)$} \\
\hline Allc2 Allergy-chronic severity & 0.18 & 0.41 & 0.41 & --- & \\
\hline Allc3 Allergy-chronic QOL impact & 0.20 & 0.41 & $0.52^{*}$ & --- & 0.75 \\
\hline \multicolumn{6}{|l|}{ Allergies-seasonal $(\mathrm{N}=146)$} \\
\hline Alls2 Allergy-seasonal severity & 0.24 & 0.43 & 0.48 & --- & \\
\hline Alls3 Allergy-seasonal QOL impact & 0.19 & 0.38 & 0.47 & --- & 0.81 \\
\hline \multicolumn{6}{|l|}{ Chronic back problems $(\mathrm{N}=115)$} \\
\hline Bp2 Back severity & 0.38 & 0.45 & 0.46 & --- & \\
\hline Bp3 Back QOL impact & 0.37 & 0.46 & $0.52^{*}$ & --- & 0.86 \\
\hline \multicolumn{6}{|l|}{ Depression (N=66) } \\
\hline De2 Depression severity & 0.32 & $0.58^{*}$ & $0.56^{\star}$ & --- & \\
\hline De3 Depression QOL impact & 0.27 & $0.55^{\star}$ & 0.51 & --- & 0.87 \\
\hline \multicolumn{6}{|l|}{ Hearing, trouble $(\mathrm{N}=81)$} \\
\hline He2 Hearing severity & 0.10 & 0.19 & 0.15 & -- & \\
\hline He3 Hearing QOL impact & 0.13 & 0.22 & 0.28 & --- & 0.52 \\
\hline \multicolumn{6}{|l|}{ Hypertension $(\mathrm{N}=168)$} \\
\hline Hy2 Hypertension severity & 0.16 & 0.39 & 0.35 & --- & \\
\hline Hy3 Hypertension QOL impact & 0.30 & 0.51 & 0.51 & --- & 0.59 \\
\hline \multicolumn{6}{|l|}{ Hypothyroidism (N=52) } \\
\hline Th2 Hypothyroidism severity & 0.02 & 0.41 & 0.42 & --- & \\
\hline Th3 Hypothyroidism QOL impact & 0.14 & 0.42 & 0.41 & --- & 0.66 \\
\hline \multicolumn{6}{|l|}{ Joint problems, hip/knee $(\mathrm{N}=94)$} \\
\hline Hk2 Hip/knee severity & 0.25 & 0.25 & 0.26 & --- & \\
\hline Hk3 Hip/knee QOL impact & 0.26 & 0.25 & 0.29 & --- & 0.87 \\
\hline \multicolumn{6}{|l|}{ Osteoporosis $(\mathrm{N}=52)$} \\
\hline Os2 Osteoporosis severity & 0.06 & 0.22 & 0.17 & --- & \\
\hline Os3 Osteoporosis QOL impact & 0.16 & 0.24 & 0.24 & --- & 0.74 \\
\hline \multicolumn{6}{|l|}{ Vision, trouble $(\mathrm{N}=61)$} \\
\hline Vi2 Vision severity & 0.19 & 0.29 & 0.28 & --- & \\
\hline Vi3 Vision QOL impact & 0.20 & 0.31 & 0.32 & --- & 0.76 \\
\hline
\end{tabular}

CC1 = Symptom measure for comorbid condition; CC2 = Severity measure for comorbid condition.

Higher scores on severity and impact items indicate greater disease severity or greater disease impact.

${ }^{a}$ Shortness of breath defined in Table 1. Higher scores indicate greater shortness of breath.

*Heterotrait correlations $r>0.51$ (absolute value) failed convergent-discriminant 1-tailed test. Median ( $r=0.62$ ) correlation from convergent triangle selected for convergent-discriminant comparisons. 
Table A3: Angina: Correlations with Prevalent Comorbid Conditions

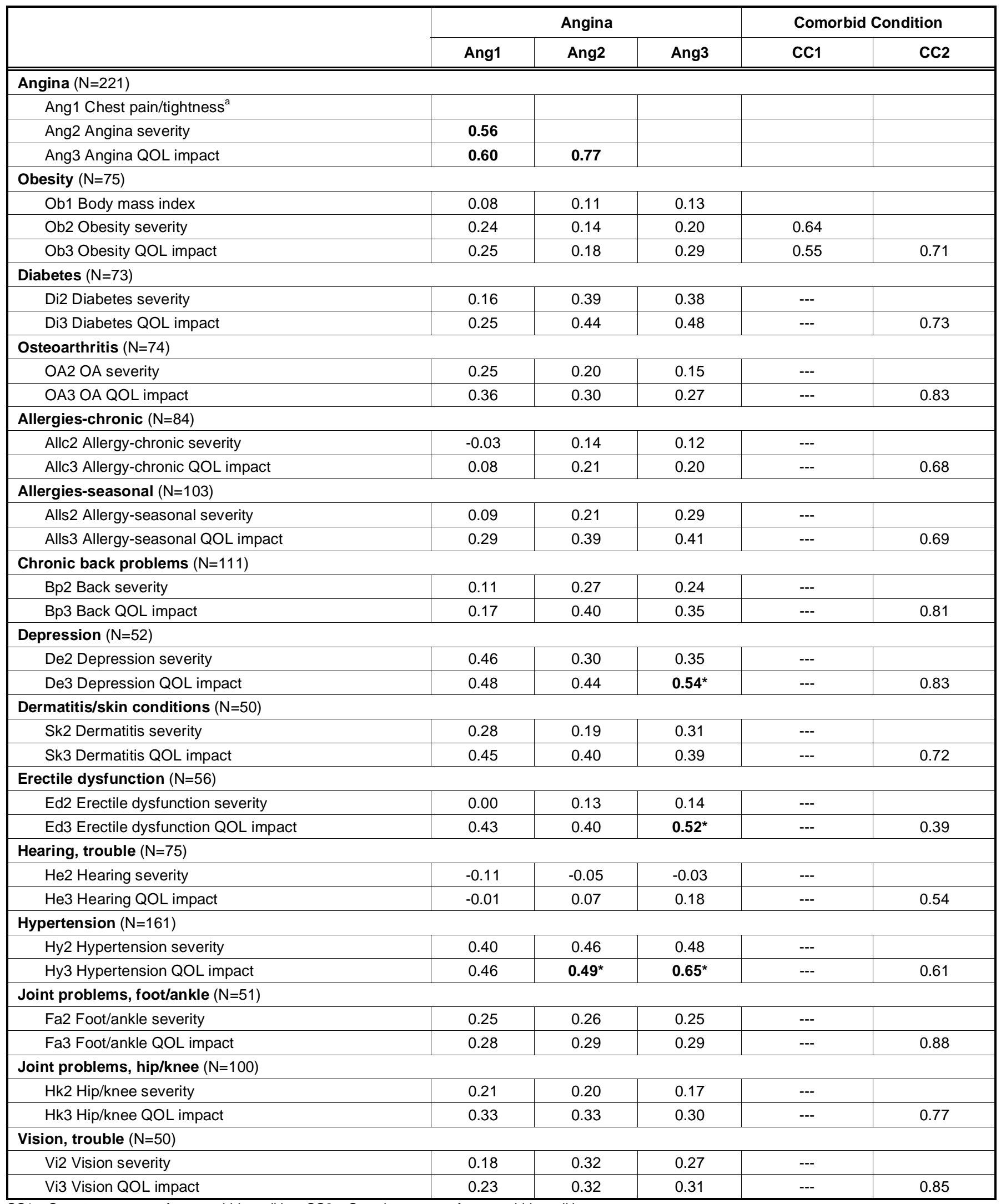

CC1 = Symptom measure for comorbid condition; CC2 = Severity measure for comorbid condition.

Higher scores on severity and impact items indicate greater disease severity or greater disease impact.

${ }^{a}$ Chest pain defined in Table 1. Higher scores indicate greater chest pain.

*Heterotrait correlations $r>0.48$ (absolute value) failed convergent-discriminant 1-tailed test. Median $(r=0.60)$ correlation from convergent triangle selected for convergent-discriminant comparisons. 
Table A4: Congestive Heart Failure: Correlations with Prevalent Comorbid Conditions

\begin{tabular}{|c|c|c|c|c|c|}
\hline & \multicolumn{3}{|c|}{ Congestive Heart Failure } & \multicolumn{2}{|c|}{ Comorbid Condition } \\
\hline & Chf1 & Chf2 & Chf3 & CC1 & CC2 \\
\hline \multicolumn{6}{|l|}{ Congestive Heart Failure $(\mathrm{N}=271)$} \\
\hline Chf2 CHF severity & 0.50 & & & & \\
\hline Chf3 CHF QOL impact & 0.53 & 0.77 & & & \\
\hline Ob2 Obesity severity & 0.29 & 0.08 & 0.03 & 0.62 & \\
\hline Ob3 Obesity QOL impact & 0.42 & 0.16 & 0.16 & 0.52 & 0.65 \\
\hline \multicolumn{6}{|l|}{ Angina $(\mathrm{N}=68)$} \\
\hline Ang2 Angina severity & $0.47^{*}$ & $0.55^{\star}$ & $0.48^{\star}$ & --- & \\
\hline Ang3 Angina QOL impact & $0.53^{*}$ & $0.54^{*}$ & $0.50^{*}$ & --- & 0.76 \\
\hline \multicolumn{6}{|l|}{ COPD $(\mathrm{N}=61)$} \\
\hline Co2 COPD severity & 0.31 & 0.05 & 0.22 & --- & \\
\hline Co3 COPD QOL impact & $0.44^{*}$ & 0.11 & 0.24 & --- & 0.84 \\
\hline \multicolumn{6}{|l|}{ Diabetes $(\mathrm{N}=92)$} \\
\hline Di2 Diabetes severity & 0.17 & 0.25 & 0.20 & --- & \\
\hline Di3 Diabetes QOL impact & 0.16 & 0.13 & 0.13 & --- & 0.61 \\
\hline \multicolumn{6}{|l|}{ Osteoarthritis $(\mathrm{N}=101)$} \\
\hline OA2 OA severity & -0.05 & -0.08 & -0.13 & --- & \\
\hline OA3 OA QOL impact & 0.15 & 0.07 & 0.01 & --- & 0.72 \\
\hline \multicolumn{6}{|l|}{ Allergies-chronic $(\mathrm{N}=95)$} \\
\hline An3 Anemia QOL impact & 0.28 & 0.11 & 0.09 & --- & 0.78 \\
\hline \multicolumn{6}{|l|}{ Benign prostatic hyperplasia $(\mathrm{N}=55)$} \\
\hline BPH2 BPH severity & 0.40 & 0.23 & 0.23 & --- & \\
\hline BPH3 BPH QOL impact & 0.41 & 0.28 & 0.26 & --- & 0.60 \\
\hline \multicolumn{6}{|l|}{ Chronic back problems $(\mathrm{N}=95)$} \\
\hline Bp2 Back severity & 0.03 & 0.18 & 0.05 & --- & \\
\hline Bp3 Back QOL impact & 0.15 & 0.15 & 0.08 & --- & 0.83 \\
\hline \multicolumn{6}{|l|}{ Dermatitis/skin conditions $(\mathrm{N}=58)$} \\
\hline Sk2 Dermatitis severity & 0.36 & 0.26 & 0.36 & --- & \\
\hline Sk3 Dermatitis QOL impact & 0.28 & 0.08 & 0.23 & --- & 0.61 \\
\hline \multicolumn{6}{|l|}{ Erectile dysfunction $(\mathrm{N}=59)$} \\
\hline Ed2 Erectile dysfunction severity & 0.19 & 0.23 & 0.26 & --- & \\
\hline Ed3 Erectile dysfunction QOL impact & 0.25 & 0.34 & 0.33 & --- & 0.64 \\
\hline \multicolumn{6}{|l|}{ Hearing, trouble $(\mathrm{N}=88)$} \\
\hline He2 Hearing severity & -0.01 & -0.05 & -0.10 & --- & \\
\hline He3 Hearing QOL impact & 0.27 & -0.03 & -0.07 & --- & 0.53 \\
\hline \multicolumn{6}{|l|}{ Hypertension $(\mathrm{N}=200)$} \\
\hline Hy2 Hypertension severity & 0.31 & 0.27 & 0.23 & --- & \\
\hline Hy3 Hypertension QOL impact & 0.41 & 0.38 & $0.45^{\star}$ & --- & 0.57 \\
\hline
\end{tabular}


(Table A4). Continued.

\begin{tabular}{|c|c|c|c|c|c|}
\hline & \multicolumn{3}{|c|}{ Congestive Heart Failure } & \multicolumn{2}{|c|}{ Comorbid Condition } \\
\hline & Chf1 & Chf2 & Chf3 & CC1 & $\mathrm{CC} 2$ \\
\hline \multicolumn{6}{|l|}{ Hypothyroidism (N=52) } \\
\hline Th2 Hypothyroidism severity & 0.42 & $0.51^{\star}$ & 0.37 & --- & \\
\hline Th3 Hypothyroidism QOL impact & 0.34 & $0.47^{\star}$ & $0.48^{\star}$ & --- & 0.72 \\
\hline \multicolumn{6}{|l|}{ Joint problems, foot/ankle $(\mathrm{N}=62)$} \\
\hline Fa2 Foot/ankle severity & 0.28 & 0.07 & 0.08 & --- & \\
\hline Fa3 Foot/ankle QOL impact & 0.40 & 0.18 & 0.15 & --- & 0.64 \\
\hline \multicolumn{6}{|l|}{ Joint problems, hip/knee (N=122) } \\
\hline Hk2 Hip/knee severity & 0.37 & 0.22 & 0.16 & --- & \\
\hline Hk3 Hip/knee QOL impact & 0.36 & 0.23 & 0.15 & --- & 0.81 \\
\hline \multicolumn{6}{|l|}{ Limb, limitations in use $(\mathrm{N}=51)$} \\
\hline Lm2 Limb severity & 0.31 & 0.40 & 0.28 & --- & \\
\hline Lm3 Limb QOL impact & 0.30 & 0.32 & 0.20 & --- & 0.84 \\
\hline \multicolumn{6}{|l|}{ Vision, trouble $(\mathrm{N}=54)$} \\
\hline Vi2 Vision severity & 0.03 & -0.19 & -0.22 & --- & \\
\hline Vi3 Vision QOL impact & 0.01 & -0.16 & -0.14 & --- & 0.62 \\
\hline
\end{tabular}

CC1 = Symptom measure for comorbid condition; CC2 = Severity measure for comorbid condition.

Higher scores on severity and impact items indicate greater disease severity or greater disease impact.

${ }^{a}$ Shortness of breath defined in Table 1. Higher scores indicate greater shortness of breath.

*Heterotrait correlations $r>0.42$ (absolute value) failed convergent-discriminant 1-tailed test. Median ( $r=0.53$ ) correlation from convergent triangle selected for convergent-discriminant comparisons.

Table A5: Diabetes: Correlations with Prevalent Comorbid Conditions

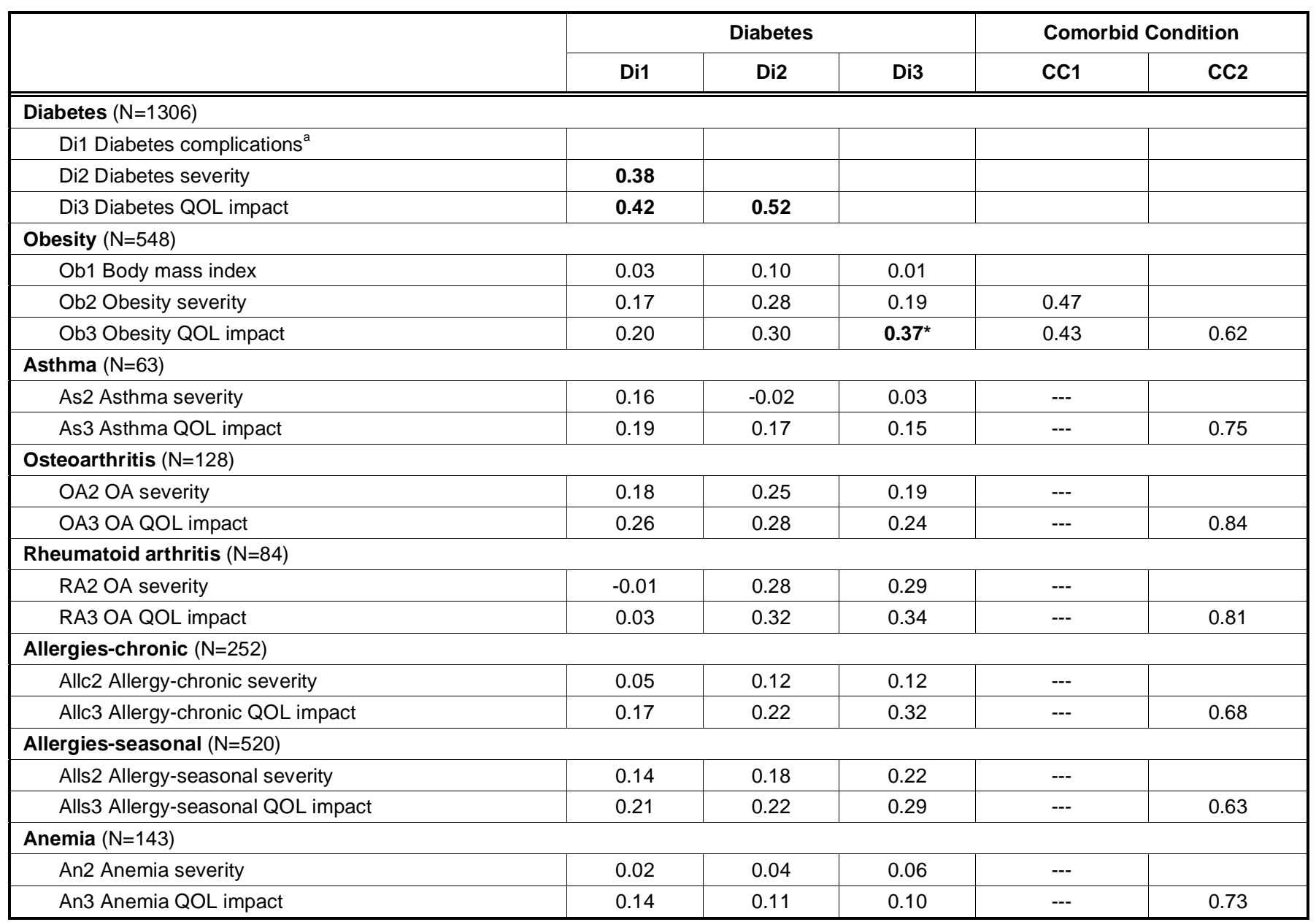


(Table A5). Continued.

\begin{tabular}{|c|c|c|c|c|c|}
\hline \multirow{3}{*}{\begin{tabular}{|l} 
Benign prostatic hyperplasia $(\mathrm{N}=145)$ \\
\end{tabular}} & \multicolumn{3}{|c|}{ Diabetes } & \multicolumn{2}{|c|}{ Comorbid Condition } \\
\hline & \multirow[t]{2}{*}{ Di1 } & \multirow[t]{2}{*}{$\mathrm{Di2}$} & \multirow[t]{2}{*}{ Di3 } & \multirow[t]{2}{*}{ CC1 } & \multirow[t]{2}{*}{$\mathrm{CC2}$} \\
\hline & & & & & \\
\hline BPH3 BPH QOL impact & $0.37^{*}$ & 0.35 & $0.44^{*}$ & --- & 0.56 \\
\hline \multicolumn{6}{|l|}{ Cancer, non-skin (N=134) } \\
\hline \multicolumn{6}{|l|}{ Chronic back problems $(\mathrm{N}=292)$} \\
\hline Bp2 Back severity & 0.21 & 0.26 & 0.26 & --- & \\
\hline Bp3 Back QOL impact & 0.24 & 0.25 & 0.31 & --- & 0.77 \\
\hline \multicolumn{6}{|l|}{ Depression $(\mathrm{N}=172)$} \\
\hline De2 Depression severity & 0.29 & 0.36 & 0.35 & --- & \\
\hline Sk3 Dermatitis QOL impact & 0.09 & 0.18 & $0.41^{*}$ & --- & 0.54 \\
\hline \multicolumn{6}{|l|}{ Erectile dysfunction $(\mathrm{N}=213)$} \\
\hline Ed2 Erectile dysfunction severity & 0.21 & 0.18 & 0.19 & --- & \\
\hline Ed3 Erectile dysfunction QOL impact & 0.24 & 0.20 & 0.29 & --- & 0.48 \\
\hline \multicolumn{6}{|l|}{ Hearing, trouble $(\mathrm{N}=239)$} \\
\hline He2 Hearing severity & -0.01 & 0.05 & 0.03 & --- & \\
\hline He3 Hearing QOL impact & 0.22 & 0.24 & 0.29 & --- & 0.48 \\
\hline \multicolumn{6}{|l|}{ Hypertension $(\mathrm{N}=900)$} \\
\hline Hy2 Hypertension severity & 0.17 & $0.38^{*}$ & 0.30 & --- & \\
\hline Hy3 Hypertension QOL impact & 0.21 & 0.28 & $0.51^{*}$ & --- & 0.45 \\
\hline Fa2 Foot/ankle severity & 0.12 & 0.27 & 0.25 & --- & \\
\hline Fa3 Foot/ankle QOL impact & 0.10 & 0.27 & 0.26 & --- & 0.76 \\
\hline \multicolumn{6}{|l|}{ Joint problems, hip/knee ( $\mathrm{N}=331)$} \\
\hline Hk2 Hip/knee severity & 0.15 & 0.17 & 0.17 & --- & \\
\hline Hk3 Hip/knee QOL impact & 0.17 & 0.20 & 0.23 & -- & 0.76 \\
\hline \multicolumn{6}{|l|}{ Limb, limitations in use $(\mathrm{N}=128)$} \\
\hline Lm2 Limb severity & 0.06 & 0.02 & 0.01 & --- & \\
\hline Lm3 Limb QOL impact & 0.11 & 0.11 & 0.11 & --- & 0.77 \\
\hline Migraine headaches $(\mathrm{N}=139)$ & & & & & \\
\hline Mi2 Migraine severity & 0.22 & 0.10 & 0.16 & --- & \\
\hline Mi3 Migraine QOL impact & 0.17 & 0.15 & 0.18 & --- & 0.88 \\
\hline Osteoporosis $(\mathrm{N}=65)$ & & & & & \\
\hline Os2 Osteoporosis severity & 0.10 & $0.39^{*}$ & 0.26 & --- & \\
\hline Os3 Osteoporosis QOL impact & -0.09 & 0.24 & 0.25 & -- & 0.63 \\
\hline Stroke $(\mathrm{N}=52)$ & & & & & \\
\hline St2 Stroke severity & 0.14 & 0.20 & 0.34 & --- & \\
\hline St3 Stroke QOL impact & 0.03 & 0.02 & 0.31 & --- & 0.74 \\
\hline Ulcer/stomach disease $(\mathrm{N}=113)$ & & & & & \\
\hline UI2 Ulcer/stomach severity & 0.13 & 0.23 & 0.25 & --- & \\
\hline UI3 Ulcer/stomach QOL impact & 0.21 & 0.31 & $0.40^{*}$ & --- & 0.73 \\
\hline
\end{tabular}


(Table A5). Continued.

\begin{tabular}{|c|c|c|c|c|c|}
\hline & \multicolumn{3}{|c|}{ Diabetes } & \multicolumn{2}{|c|}{ Comorbid Condition } \\
\hline & Di1 & Di2 & Di3 & CC1 & CC2 \\
\hline \multicolumn{6}{|l|}{ Vision, trouble $(\mathrm{N}=160)$} \\
\hline Vi2 Vision severity & 0.18 & 0.05 & 0.18 & --- & \\
\hline Vi3 Vision QOL impact & 0.26 & 0.11 & 0.32 & --- & 0.66 \\
\hline
\end{tabular}

CC1 = Symptom measure for comorbid condition; CC2 = Severity measure for comorbid condition.

Higher scores on severity and impact items indicate greater disease severity or greater disease impact.

${ }^{a}$ Number of diabetes complications defined in Table 1.

*Heterotrait correlations $r>0.36$ (absolute value) failed convergent-discriminant 1-tailed test. Median ( $r=0.42)$ correlation from convergent triangle selected for convergent-discriminant comparisons.

Table A6: Chronic Kidney Disease (Stages 3-5): Correlations with Prevalent Comorbid Conditions

\begin{tabular}{|c|c|c|c|c|c|}
\hline & \multicolumn{3}{|c|}{ Chronic Kidney Disease } & \multicolumn{2}{|c|}{ Comorbid Condition } \\
\hline & Kd1 & Kd2 & Kd3 & $\mathrm{CC} 1$ & $\mathrm{CC} 2$ \\
\hline \multicolumn{6}{|l|}{ CKD $(\mathrm{N}=147)$} \\
\hline Kd2 CKD severity & -0.45 & & & & \\
\hline Kd3 CKD QOL impact & -0.39 & 0.72 & & & \\
\hline Ob1 Body mass index & 0.02 & 0.20 & 0.23 & & \\
\hline Ob2 Obesity severity & -0.05 & 0.26 & $0.40^{*}$ & 0.57 & \\
\hline Ob3 Obesity QOL impact & 0.02 & 0.22 & 0.28 & 0.47 & 0.76 \\
\hline \multicolumn{6}{|l|}{ Diabetes $(\mathrm{N}=56)$} \\
\hline OA2 OA severity & 0.09 & -0.01 & 0.13 & --- & \\
\hline OA3 OA QOL impact & 0.05 & -0.06 & 0.08 & --- & 0.81 \\
\hline \multicolumn{6}{|l|}{ Allergies-seasonal $(\mathrm{N}=60)$} \\
\hline Alls2 Allergy-seasonal severity & -0.18 & 0.21 & $0.32^{*}$ & --- & \\
\hline Alls3 Allergy-seasonal QOL impact & -0.24 & $0.32^{\star}$ & $0.39^{*}$ & --- & 0.72 \\
\hline \multicolumn{6}{|l|}{ Anemia $(\mathrm{N}=56)$} \\
\hline An2 Anemia severity & -0.30 & $0.49^{*}$ & $0.48^{*}$ & --- & \\
\hline An3 Anemia QOL impact & -0.22 & $0.37^{\star}$ & $0.46^{*}$ & --- & 0.82 \\
\hline \multicolumn{6}{|l|}{ Chronic back problems $(\mathrm{N}=51)$} \\
\hline Hk2 Hip/knee severity & -0.04 & 0.00 & 0.18 & --- & \\
\hline Hk3 Hip/knee QOL impact & 0.08 & 0.02 & 0.27 & --- & 0.79 \\
\hline
\end{tabular}

CC1 = Symptom measure for comorbid condition; CC2 = Severity measure for comorbid condition.

Higher scores on severity and impact items indicate greater disease severity or greater disease impact.

${ }^{a}$ Estimated glomerular filtration rate defined in Table 1. Lower eGFR indicates worse kidney function.

*Heterotrait correlations $\mathrm{r}<-0.31$ (Kd1 column) or $r>0.31$ (Kd2 and $\mathrm{Kd} 3$ columns) failed convergent-discriminant 1 -tailed test. Median ( $r=-0.45$ (Kd1 tests) or $\mathrm{r}=0.45$

(Kd2 and Kd3 columns) correlation from convergent triangle selected for convergent-discriminant comparisons. 
Table A7: Osteoarthritis: Correlations with Prevalent Comorbid Conditions

\begin{tabular}{|c|c|c|c|c|c|}
\hline & \multicolumn{3}{|c|}{ Osteoarthritis } & \multicolumn{2}{|c|}{ Comorbid Condition } \\
\hline \multicolumn{6}{|l|}{ Osteoarthritis ( $\mathrm{N}=1026)$} \\
\hline \multicolumn{6}{|l|}{ OA1 Joint pain ${ }^{a}$} \\
\hline OA2 OA severity & 0.51 & & & & \\
\hline Ob1 Body mass index & 0.05 & 0.15 & 0.21 & & \\
\hline Ob2 Obesity severity & 0.14 & 0.22 & 0.25 & 0.55 & \\
\hline Ob3 Obesity QOL impact & 0.19 & 0.24 & 0.32 & 0.39 & 0.60 \\
\hline \multicolumn{6}{|l|}{ Asthma $(\mathrm{N}=54)$} \\
\hline \multicolumn{6}{|l|}{ Diabetes (N=202) } \\
\hline Di2 Diabetes severity & 0.12 & 0.12 & 0.09 & --- & \\
\hline Di3 Diabetes QOL impact & 0.17 & 0.12 & 0.18 & --- & 0.53 \\
\hline \multicolumn{6}{|l|}{ Allergies-chronic ( $\mathrm{N}=300)$} \\
\hline Allc2 Allergy-chronic severity & 0.10 & 0.07 & 0.09 & --- & \\
\hline Allc3 Allergy-chronic QOL impact & 0.17 & 0.04 & 0.14 & --- & 0.62 \\
\hline \multicolumn{6}{|l|}{ Allergies-seasonal (N=469) } \\
\hline Alls2 Allergy-seasonal severity & 0.20 & 0.19 & 0.17 & --- & \\
\hline BPH3 BPH QOL impact & 0.25 & 0.22 & 0.22 & --- & 0.46 \\
\hline \multicolumn{6}{|l|}{ Cancer, non-skin $(\mathrm{N}=134)$} \\
\hline Ca2 Cancer severity & -0.05 & 0.05 & 0.11 & --- & \\
\hline Ca3 Cancer QOL impact & -0.05 & 0.07 & 0.17 & --- & 0.85 \\
\hline \multicolumn{6}{|l|}{ Chronic back problems $(\mathrm{N}=425)$} \\
\hline Bp2 Back severity & 0.39 & $0.52^{\star}$ & $0.48^{*}$ & --- & \\
\hline Bp3 Back QOL impact & 0.38 & $0.48^{*}$ & $0.57^{*}$ & --- & 0.81 \\
\hline \multicolumn{6}{|l|}{ Depression $(\mathrm{N}=202)$} \\
\hline De2 Depression severity & 0.15 & 0.26 & 0.29 & --- & \\
\hline De3 Depression QOL impact & 0.12 & 0.27 & 0.31 & --- & 0.83 \\
\hline \multicolumn{6}{|l|}{ Dermatitis/skin conditions ( $N=146)$} \\
\hline Sk2 Dermatitis severity & 0.07 & 0.15 & 0.21 & --- & \\
\hline Sk3 Dermatitis QOL impact & 0.11 & 0.10 & 0.23 & --- & 0.54 \\
\hline \multicolumn{6}{|l|}{ Erectile dysfunction $(\mathrm{N}=92)$} \\
\hline Ed2 Erectile dysfunction severity & 0.26 & 0.20 & 0.27 & --- & \\
\hline Ed3 Erectile dysfunction QOL impact & 0.19 & 0.30 & 0.38 & --- & 0.51 \\
\hline
\end{tabular}




\begin{tabular}{|c|c|c|c|c|c|}
\hline & \multicolumn{3}{|c|}{ Osteoarthritis } & \multicolumn{2}{|c|}{ Comorbid Condition } \\
\hline & OA1 & OA2 & OA3 & CC1 & $\mathrm{CC2}$ \\
\hline FM2 Fibromyalgia severity & $0.48^{*}$ & $0.53^{*}$ & $0.50^{*}$ & --- & \\
\hline FM3 Fibromyalgia QOL impact & $0.57^{*}$ & $0.50^{*}$ & $0.53^{*}$ & --- & 0.86 \\
\hline He2 Hearing severity & 0.20 & 0.16 & 0.11 & --- & \\
\hline He3 Hearing QOL impact & 0.18 & 0.19 & 0.24 & --- & 0.58 \\
\hline \multicolumn{6}{|l|}{ Hypertension ( $\mathrm{N}=566)$} \\
\hline Hy2 Hypertension severity & 0.21 & 0.28 & 0.27 & --- & \\
\hline Th3 Hypothyroidism QOL impact & 0.25 & 0.27 & 0.29 & --- & 0.62 \\
\hline \multicolumn{6}{|l|}{ Irritable bowel syndrome (N=162) } \\
\hline Ib2 IBS severity & 0.19 & 0.13 & 0.12 & --- & \\
\hline Ib3 IBS QOL impact & 0.24 & 0.21 & 0.26 & --- & 0.74 \\
\hline \multicolumn{6}{|l|}{ Joint problems, foot/ankle ( $\mathrm{N}=251)$} \\
\hline Fa2 Foot/ankle severity & 0.26 & 0.31 & 0.31 & --- & \\
\hline Fa3 Foot/ankle QOL impact & 0.33 & 0.38 & $0.47^{\star}$ & --- & 0.78 \\
\hline \multicolumn{6}{|l|}{ Joint problems, hip/knee (N=638) } \\
\hline \multicolumn{6}{|l|}{ Migraine headaches $(\mathrm{N}=216)$} \\
\hline Mi2 Migraine severity & 0.22 & 0.21 & 0.21 & --- & \\
\hline Mi3 Migraine QOL impact & 0.21 & 0.17 & 0.22 & --- & 0.86 \\
\hline \multicolumn{6}{|l|}{ Osteoporosis ( $\mathrm{N}=146)$} \\
\hline Os2 Osteoporosis severity & 0.44 & $0.49^{*}$ & $0.47^{*}$ & --- & \\
\hline Os3 Osteoporosis QOL impact & 0.36 & 0.42 & $0.54^{\star}$ & --- & 0.70 \\
\hline \multicolumn{6}{|l|}{ Ulcer/stomach disease $(\mathrm{N}=154)$} \\
\hline UI2 Ulcer/stomach severity & 0.25 & 0.27 & 0.30 & --- & \\
\hline UI3 Ulcer/stomach QOL impact & 0.22 & 0.19 & 0.26 & --- & 0.78 \\
\hline \multicolumn{6}{|l|}{ Vision, trouble $(\mathrm{N}=129)$} \\
\hline Vi2 Vision severity & 0.20 & 0.14 & 0.08 & --- & \\
\hline Vi3 Vision QOL impact & 0.23 & 0.20 & 0.28 & --- & 0.64 \\
\hline
\end{tabular}

CC1 = Symptom measure for comorbid condition; CC2 = Severity measure for comorbid condition.

Higher scores on severity and impact items indicate greater disease severity or greater disease impact.

a Joint pain defined in Table 1. Higher scores indicate greater joint pain.

*Heterotrait correlations $r>0.45$ (absolute value) failed convergent-discriminant 1 -tailed test. Median ( $r=0.51$ ) correlation from convergent triangle selected for convergent-discriminant comparisons. 
Table A8: Rheumatoid Arthritis: Correlations with Prevalent Comorbid Conditions

\begin{tabular}{|c|c|c|c|c|c|}
\hline & \multicolumn{3}{|c|}{ Rheumatoid Arthritis } & \multicolumn{2}{|c|}{ Comorbid Condition } \\
\hline \multicolumn{6}{|l|}{ Rheumatoid arthritis (N=493) } \\
\hline RA2 RA severity & 0.53 & & & & \\
\hline RA3 RA QOL impact & 0.49 & 0.78 & & & \\
\hline Ob1 Body mass index & 0.21 & 0.24 & 0.25 & & \\
\hline Ob2 Obesity severity & 0.31 & 0.33 & 0.31 & 0.58 & \\
\hline Ob3 Obesity QOL impact & 0.23 & 0.36 & 0.37 & 0.45 & 0.72 \\
\hline \multicolumn{6}{|l|}{ Diabetes $(\mathrm{N}=90)$} \\
\hline Di2 Diabetes severity & 0.00 & 0.11 & 0.07 & --- & \\
\hline OA3 OA QOL impact & 0.33 & 0.32 & 0.45 & --- & 0.83 \\
\hline \multicolumn{6}{|l|}{ Allergies-chronic ( $\mathrm{N}=156)$} \\
\hline Allc2 Allergy-chronic severity & 0.31 & 0.28 & 0.24 & --- & \\
\hline Allc3 Allergy-chronic QOL impact & 0.26 & 0.25 & 0.33 & --- & 0.68 \\
\hline \multicolumn{6}{|l|}{ Allergies-seasonal $(\mathrm{N}=220)$} \\
\hline Alls2 Allergy-seasonal severity & 0.19 & 0.30 & 0.22 & --- & \\
\hline Alls3 Allergy-seasonal QOL impact & 0.28 & 0.32 & 0.31 & --- & 0.76 \\
\hline \multicolumn{6}{|l|}{ Anemia $(\mathrm{N}=91)$} \\
\hline An2 Anemia severity & 0.31 & 0.28 & 0.23 & --- & \\
\hline Bp3 Back QOL impact & 0.45 & $0.48^{\star}$ & $0.55^{\star}$ & --- & 0.84 \\
\hline \multicolumn{6}{|l|}{ Depression $(\mathrm{N}=99)$} \\
\hline De2 Depression severity & 0.26 & 0.42 & 0.41 & --- & \\
\hline De3 Depression QOL impact & 0.29 & 0.34 & 0.42 & --- & 0.87 \\
\hline \multicolumn{6}{|l|}{ Dermatitis/skin conditions (N=85) } \\
\hline Sk2 Dermatitis severity & 0.10 & 0.21 & 0.17 & --- & \\
\hline Sk3 Dermatitis QOL impact & 0.27 & 0.30 & 0.27 & --- & 0.77 \\
\hline \multicolumn{6}{|l|}{ Erectile dysfunction $(\mathrm{N}=50)$} \\
\hline Ed2 Erectile dysfunction severity & 0.23 & 0.23 & 0.17 & --- & \\
\hline Ed3 Erectile dysfunction QOL impact & $0.47^{*}$ & 0.40 & 0.34 & --- & 0.51 \\
\hline \multicolumn{6}{|l|}{ Fibromyalgia $(\mathrm{N}=72)$} \\
\hline FM2 Fibromyalgia severity & $0.49^{*}$ & $0.49^{*}$ & $0.47^{\star}$ & --- & \\
\hline FM3 Fibromyalgia QOL impact & $0.49^{*}$ & $0.49^{*}$ & $0.51^{*}$ & --- & 0.91 \\
\hline \multicolumn{6}{|l|}{ Hearing, trouble $(\mathrm{N}=77)$} \\
\hline He2 Hearing severity & 0.03 & 0.19 & 0.13 & --- & \\
\hline He3 Hearing QOL impact & 0.13 & 0.29 & 0.37 & --- & 0.53 \\
\hline \multicolumn{6}{|l|}{ Hypertension (N=269) } \\
\hline Hy2 Hypertension severity & 0.26 & 0.36 & 0.34 & --- & \\
\hline Hy3 Hypertension QOL impact & 0.32 & 0.41 & 0.45 & --- & 0.58 \\
\hline
\end{tabular}


(Table A8). Continued.

\begin{tabular}{|c|c|c|c|c|c|}
\hline & \multicolumn{3}{|c|}{ Rheumatoid Arthritis } & \multicolumn{2}{|c|}{ Comorbid Condition } \\
\hline \multicolumn{6}{|l|}{ Hypothyroidism (N=90) } \\
\hline Th3 Hypothyroidism QOL impact & 0.24 & 0.21 & 0.30 & --- & 0.75 \\
\hline \multicolumn{6}{|l|}{ Irritable bowel syndrome $(\mathrm{N}=74)$} \\
\hline \multicolumn{6}{|l|}{ Joint problems, foot/ankle $(\mathrm{N}=167)$} \\
\hline Fa2 Foot/ankle severity & 0.33 & $0.49^{*}$ & $0.46^{\star}$ & --- & \\
\hline Fa3 Foot/ankle QOL impact & 0.31 & 0.44 & $0.49^{*}$ & --- & 0.80 \\
\hline \multicolumn{6}{|l|}{ Joint problems, hip/knee (N=275) } \\
\hline Hk2 Hip/knee severity & 0.40 & 0.38 & 0.43 & --- & \\
\hline Lm3 Limb QOL impact & 0.25 & 0.25 & 0.43 & --- & 0.70 \\
\hline \multicolumn{6}{|l|}{ Migraine headaches $(\mathrm{N}=108)$} \\
\hline Mi2 Migraine severity & 0.15 & 0.12 & 0.12 & --- & \\
\hline Mi3 Migraine QOL impact & 0.29 & 0.20 & 0.19 & --- & 0.84 \\
\hline \multicolumn{6}{|l|}{ Osteoporosis $(\mathrm{N}=76)$} \\
\hline Os2 Osteoporosis severity & 0.38 & $0.52^{*}$ & $0.46^{*}$ & --- & \\
\hline Os3 Osteoporosis QOL impact & 0.38 & 0.42 & $0.46^{\star}$ & --- & 0.72 \\
\hline \multicolumn{6}{|l|}{ Ulcer/stomach disease $(\mathrm{N}=76)$} \\
\hline UI2 Ulcer/stomach severity & 0.32 & $0.46^{*}$ & 0.44 & --- & \\
\hline UI3 Ulcer/stomach QOL impact & 0.27 & 0.42 & $0.48^{\star}$ & --- & 0.78 \\
\hline
\end{tabular}

CC1 = Symptom measure for comorbid condition; CC2 = Severity measure for comorbid condition .

Higher scores on severity and impact items indicate greater disease severity or greater disease impact.

a Joint pain defined in Table 1. Higher scores indicate greater joint pain.

*Heterotrait correlations $r>0.45$ (absolute value) failed convergent-discriminant 1 -tailed test. Median ( $r=0.53$ ) correlation from convergent triangle selected for convergent-discriminant comparisons.

\section{REFERENCES}

[1] National Quality Forum. Multiple chronic conditions measurement framework. Washington, DC: National Quality Forum 2012.

[2] Gijsen R, Hoeymans N, Schellevis FG, Ruwaard D, Satariano WA, van den Bos GA. Causes and consequences of comorbidity: a review. J Clin Epidemiol 2001; 54: 661-74. http://dx.doi.org/10.1016/S0895-4356(00)00363-2

[3] Marengoni A, Angleman S, Melis R, Mangialasche F, Karp A, Garmen A, et al. Aging with multimorbidity: a systematic review of the literature. Ageing Res Rev 2011; 10: 430-9. http://dx.doi.org/10.1016/j.arr.2011.03.003

[4] Salive ME. Multimorbidity in older adults. Epidemiol Rev 2013; 35: 75-83.

http://dx.doi.org/10.1093/epirev/mxs009

[5] Safford MM, Allison JJ, Kiefe Cl. Patient complexity: more than comorbidity. The vector model of complexity. J Gen Intern Med 2007; 22 Suppl 3: 382-90. http://dx.doi.org/10.1007/s11606-007-0307-0

[6] Boyd CM, Darer J, Boult C, Fried LP, Boult L, Wu AW. Clinical practice guidelines and quality of care for older patients with multiple comorbid diseases: implications for pay for performance. JAMA 2005; 294: 716-24. http://dx.doi.org/10.1001/jama.294.6.716
[7] Tinetti ME, Studenski SA. Comparative effectiveness research and patients with multiple chronic conditions. N Engl J Med 2011; 364: 2478-81. http://dx.doi.org/10.1056/NEJMp1100535

[8] de Groot V, Beckerman H, Lankhorst GJ, Bouter LM. How to measure comorbidity. A critical review of available methods. $\mathrm{J}$ Clin Epidemiol 2003; 56: 221-9. http://dx.doi.org/10.1016/S0895-4356(02)00585-1

[9] Fortin M, Lapointe L, Hudon C, Vanasse A, Ntetu AL, Maltais D. Multimorbidity and quality of life in primary care: a systematic review. Health Qual Life Outcomes 2004; 2: 51. http://dx.doi.org/10.1186/1477-7525-2-51

[10] Charlson ME, Pompei P, Ales KL, MacKenzie CR. A new method of classifying prognostic comorbidity in longitudinal studies: development and validation. J Chronic Dis 1987; 40: 373-83.

http://dx.doi.org/10.1016/0021-9681(87)90171-8

[11] Diederichs C, Berger K, Bartels DB. The measurement of multiple chronic diseases--a systematic review on existing multimorbidity indices. J Gerontol A Biol Sci Med Sci 2011; 66: 301-11.

\section{http://dx.doi.org/10.1093/gerona/gla208}

[12] Working Group on Health Outcomes for Older Persons with Multiple Chronic Conditions. Universal health outcome measures for older persons with multiple chronic conditions. 
J Am Geriatr Soc 2012; 60: 2333-41.

http://dx.doi.org/10.1111/j.1532-5415.2012.04240.x

[13] U.S. Department of Health and Human Services, Food and Drug Administration. Guidance for industry - Patient-reported outcome measures: Use in medical product development to support labeling claims. Rockville, MD: Food and Drug Administration, 2009.

[14] Bellamy N, Buchanan WW, Goldsmith CH, Campbell J, Stitt LW. Validation study of WOMAC: a health status instrument for measuring clinically important patient relevant outcomes to antirheumatic drug therapy in patients with osteoarthritis of the hip or knee. J Rheumatol 1988; 15: 1833-40.

[15] Jones PW, Quirk FH, Baveystock CM, Littlejohns P. A selfcomplete measure of health status for chronic airflow limitation. The St. George's Respiratory Questionnaire. Am Rev Respir Dis 1992; 145: 1321-7.

http://dx.doi.org/10.1164/ajrccm/145.6.1321

[16] Wilson IB, Cleary PD. Linking clinical variables with healthrelated quality of life. A conceptual model of patient outcomes. JAMA 1995; 273: 59-65. http://dx.doi.org/10.1001/jama.1995.03520250075037

[17] Nathan RA, Sorkness CA, Kosinski M, Schatz M, Li JT, Marcus P, et al. Development of the Asthma Control Test: a survey for assessing asthma control. J Allergy Clin Immunol 2004; 113: 59-65.

http://dx.doi.org/10.1016/j.jaci.2003.09.008

[18] Rector TS, Kubo SH, Cohn JN. Patients' self-assessment of their congestive heart failure: Content, reliability, and validity of a new measure, the Minnesota Living with Heart Failure questionnaire. Heart Failure 1987; 3: 198-209.

[19] Hays RD, Kallich JD, Mapes DL, Coons SJ, Carter WB. Development of the Kidney Disease Quality of Life (KDQOL) instrument. Qual Life Res 1994; 3: 329-38.

http://dx.doi.org/10.1007/BF00451725

[20] Ware JE Jr. Standards for validating health measures: Definition and content. J Chronic Dis 1987; 40: 473-80.

http://dx.doi.org/10.1016/0021-9681(87)90003-8

[21] Ware JE Jr., Gandek B, Guyer R, Deng N. Standardizing disease-specific quality of life measures across multiple chronic conditions: Development and initial evaluation of the QOL Disease Impact Scale (QDIS®). In review

[22] EuroQol Group. EuroQol--a new facility for the measurement of health-related quality of life. Health Policy 1990; 16: 199208.

http://dx.doi.org/10.1016/0168-8510(90)90421-9

[23] Cella D, Riley W, Stone A, Rothrock N, Reeve B, Yount S, et al. The Patient-reported Outcomes Measurement Information System (PROMIS) developed and tested its first wave of adult self-reported health outcome item banks: 2005-2008. J Clin Epidemiol 2010; 63: 1179-94.

http://dx.doi.org/10.1016/j.jclinepi.2010.04.011

[24] Ware JE Jr., Sherbourne CD. The MOS 36-item Short-Form Health Survey (SF-36). I. Conceptual framework and item selection. Med Care 1992; 30: 473-83. http://dx.doi.org/10.1097/00005650-199206000-00002

[25] Wiebe S, Guyatt G, Weaver B, Matijevic S, Sidwell C. Comparative responsiveness of generic and specific qualityof-life instruments. J Clin Epidemiol 2003; 56: 52-60. http://dx.doi.org/10.1016/S0895-4356(02)00537-1
[26] Ware JE Jr., Guyer R, Harrington M, Boulanger R. Evaluation of a more comprehensive survey item bank for standardizing disease-specific impact comparisons across chronic conditions. Qual Life Res 2012; 21: 27-8.

[27] Ware JE Jr., Harrington M, Guyer R, Boulanger R. A system for integrating generic and disease-specific patient-reported outcome (PRO) measures. Mapi Research Institute Patient Reported Outcomes Newsletter 2012: 1-4.

[28] Brown TA. Confirmatory Factor Analysis for Applied Research. 2nd ed. New York: Guilford Press, 2015.

[29] Deng N, Anatchkova MD, Waring ME, Han KT, Ware JE,Jr. Testing item response theory invariance of the standardized Quality-of-life Disease Impact Scale (QDIS®) in acute coronary syndrome patients: Differential functioning of items and test. Qual Life Res 2015; 24: 1809-22. http://dx.doi.org/10.1007/s11136-015-0916-8

[30] GfK United States. KnowledgePanel Design Summary. http://www gfk com/Documents/GfK-KnowledgePanelDesign-Summary.pdf; Accessed November 3, 2014.

[31] AAPOR Standards Committee Task Force. Research Synthesis: AAPOR Report on Online Panels. Public Opinion Quarterly 2010; 74: 711-81.

http://dx.doi.org/10.1093/pog/nfq048

[32] Campbell DT, Fiske DW. Convergent and discriminant validation by the multitrait-multimethod matrix. Psychol Bull 1959; 56: 81-105. http://dx.doi.org/10.1037/h0046016

[33] Lin P, Ware JE Jr, Meyer K, Richardson M, Bjorner JB. Methods for psychometric and clinical evaluations of CATbased measures of disease impact in chronic kidney disease (CKD). Value Health 2010; 13: A244. http://dx.doi.org/10.1016/S1098-3015(11)71866-6

[34] Deng N, Allison JJ, Fang HJ, Ash AS, Ware JE Jr. Using the bootstrap to establish statistical significance for relative validity comparisons among patient-reported outcome measures. Health Qual Life Outcomes 2013; 11: 89. http://dx.doi.org/10.1186/1477-7525-11-89

[35] Frei A, Muggensturm P, Putcha N, Siebeling L, Zoller M, Boyd $\mathrm{CM}$ et al. Five comorbidities reflected the health status in patients with chronic obstructive pulmonary disease: the newly developed COMCOLD index. J Clin Epidemiol 2014; 67: 904-11. http://dx.doi.org/10.1016/j.jclinepi.2014.03.005

[36] Ware JE Jr., Gandek B, Kulasekaran A, Guyer R. Evaluation of smoking-specific and generic quality of life measures in current and former smokers in Germany and the United States. Health Qual Life Outcomes 2015; 13: 128. http://dx.doi.org/10.1186/s12955-015-0316-3

[37] Bayliss EA, Ellis JL, Steiner JF. Subjective assessments of comorbidity correlate with quality of life health outcomes: initial validation of a comorbidity assessment instrument. Health Qual Life Outcomes 2005; 3: 51. http://dx.doi.org/10.1186/1477-7525-3-51

[38] Spertus JA, Winder JA, Dewhurst TA, Deyo RA, Prodzinski J, McDonell M, et al. Development and evaluation of the Seattle Angina Questionnaire: a new functional status measure for coronary artery disease. J Am Coll Cardiol 1995; 25: 333-41. http://dx.doi.org/10.1016/0735-1097(94)00397-9

(C) 2016 Ware et al.; Licensee Lifescience Global.

This is an open access article licensed under the terms of the Creative Commons Attribution Non-Commercial License (http://creativecommons.org/licenses/by-nc/3.0/) which permits unrestricted, non-commercial use, distribution and reproduction in any medium, provided the work is properly cited. 